\title{
A Framework Interpreting Bender Element Tests, Combining Time-Domain and Frequency-Domain Methods
}

\begin{abstract}
Bender element (BE) testing is a powerful and increasingly common laboratory technique for determining the shear S-wave velocity of geomaterials. There are several advantages of BE testing, but there is no standard developed for the testing procedures or for the interpretation of the results. This leads to high degree of uncertainty and subjectivity in the interpretation. In this paper, the authors review the most common methods for the interpretation of BE tests, discuss some important technical requirements to minimize errors, and propose a practical framework for $\mathrm{BE}$ testing, based on the comparison of different interpretation techniques in order to obtain the most reliable value for the travel time. This new procedure consists of the application of a methodical, systematic, and objective approach for the interpretation of the results, in the time and frequency domains. The use of an automated tool enables unbiased information to be obtained regarding variations in the results to assist in the decision of the travel time. Two natural soils were tested: residual soil from Porto granite, and Toyoura sand. Specimens were subjected to the same isotropic stress conditions and the results obtained provided insights on the effects of soil type and confining stress on the interpretation of BE results; namely, the differences in testing dry versus saturated soils, and in testing uniform versus well-graded soils.
\end{abstract}

KEYWORDS: shear wave velocities, bender elements, time-domain and frequency-domain techniques

\section{Introduction}

In the past couple of decades, it has been recognized that the socalled "elastic" stress-strain response of practically all soils and soft rocks is in fact highly nonlinear. This has led to the development of methods of foundation analysis and settlement/ deformation prediction that take this into account, such that stiffness nonlinearity is now routinely incorporated into many standard computer codes. These achievements have been paralleled by developments in both in situ and laboratory testing methods that allow the details of the stress-strain response to be examined, even at strains as low as $10^{-6}$. In the laboratory, the most important advances in this context have been:

- improvements in resonant column testing;

- improvements in internal strain-measuring instrumentation in triaxial tests; and

- the widespread adoption of methods of determining the shear wave velocity $\left(V_{s}\right)$ in triaxial and oedometer tests, from which the initial tangent stiffness (also called the smallstrain stiffness, $G_{o}$ or $G_{\max }$ ) can be determined directly.

The most widely used method for determining $V_{s}$ in the laboratory is the bender element (BE) method.

The BE method was introduced into general soil testing practice by Shirley and co-workers (Shirley 1978; Shirley and Hampton

Manuscript received January 9, 2007; accepted for publication October 22, 2008; published online December 2008.

${ }^{1}$ Associate Professor, Universidade do Porto, Faculdade Engenharia, DECivil, Rua Dr Roberto Frias, 4200-465 Porto, Portugal, e-mail: viana@fe.up.pt

${ }^{2}$ Senior Research Assistant, Universidade do Porto, Faculdade Engenharia, DECivil, Rua Dr Roberto Frias, 4200-465 Porto, Portugal, e-mail: cristiana@fe.up.pt

${ }^{3}$ Professor, School of Civil \& Resource Engineering, The University of Western Australia, 35 Stirling Highway, Crawley, WA 6009, Australia. Tel.: +618 6488 3519, Fax: +618 64881044 e-mail: fahey@civil.uwa.edu.au
1978). Dyvik and Madshus (1985) presented a more detailed BE design model, which forms the basis of much of the subsequent development. The advantage of the $\mathrm{BE}$ technique is its apparent simplicity: a single BE is excited at one end of a specimen using a simple pulse excitation, and the time required for this signal to be registered by the receiving $\mathrm{BE}$ at the other end is simply read off an oscilloscope, to obtain the travel time, and hence the shear wave velocity. However, as the method was implemented by both research and commercial laboratories around the world, it gradually became apparent that there were various issues to be resolved regarding the hardware used, the testing procedures, and the interpretation of the results. With regard to the BEs, the issues that have been discussed include the optimum thickness of the elements, how the layers of the element should be wired (parallel or series), and the details of the insulation, mounting, protrusion distance, shielding, and grounding. There has also been considerable discussion with regard to the choice of ancillary hardware - function generators, power and signal amplifiers, oscilloscopes, A-D convertersand the form and voltage of the driving signal. Recently, there has been much discussion on the details of the test procedure and the most appropriate method of interpreting the results. Good summaries of these issues are provided by Lee and Santamarina (2005), Arulnathan et al. (1998), and Leong et al. (2005), among others. Many other researchers have published studies dealing with shear wave velocity measurement in the laboratory, not only in the triaxial apparatus, but also in the oedometer (Fam and Santamarina 1995; Zeng and Grolewski 2005), direct shear apparatus (Dyvik and Olsen 1989), the centrifuge (Ismail and Hourani 2003), the hollow cylinder apparatus (Di Benedetto et al. 1999; Geoffroy et al. 2003), true triaxial and cubical cell apparatuses (Ismail et al. 2005; Sadek 2006), and the resonant column apparatus (Souto et al. 1994; Santos 1999; Fam et al. 2002; Ferreira et al. 2007).

Interest in in situ geophysical (seismic) testing for geotechnical engineering purposes has been growing for a number of years (Stokoe and Woods 1972; Anderson and Woods 1975; Burland 


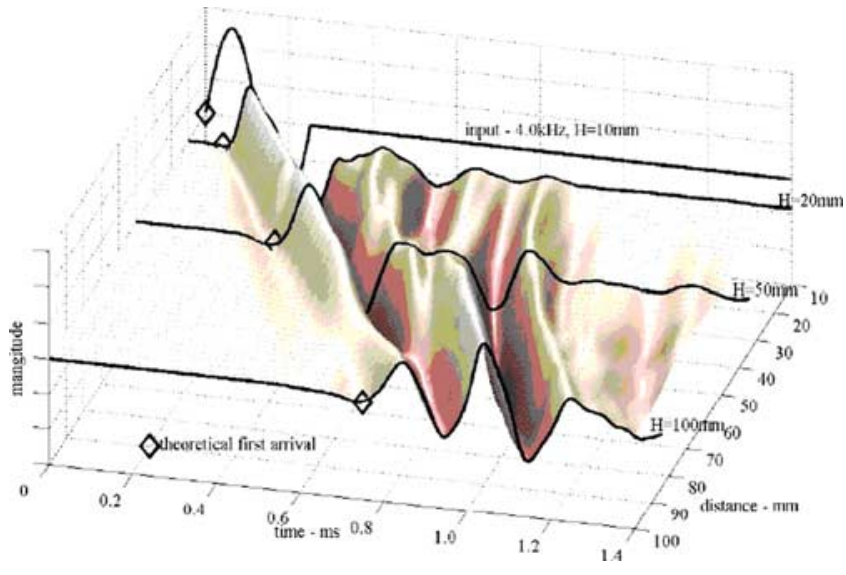

FIG. 1-Typical bender element traces: numerical simulation of wave propagation in the main axis of a 100 by $75 \mathrm{~mm}$-idealized soil sample, with nonabsorbent lateral surface (Rio 2006).

1989; Jamiolkowski et al. 1995; Sully and Campanella 1995; Hight et al. 1997; Foti et al. 2002; Stokoe et al. 2004; Viana da Fonseca et al. 2006). Many of the approaches used to interpret in situ geophysical tests are relevant in the interpretation of BE tests. Because of this, the paper also focuses on applying some of the principles used in in situ geophysical testing to interpretation of BE tests.

This paper describes a study in which BE testing was carried out on two soils: a residual soil from Porto granite, and Toyoura sand from Japan. Different testing procedures were used, and a number of methods of interpreting test results were applied. The aim of the work was to compare the various testing and interpretation methods, to determine if a "best" test procedure and interpretation method could be established for BE testing in these soils. The paper describes a practical framework for BE testing, based on the comparison of different interpretation techniques in order to obtain a reliable value for the travel time, using an objective and systematic approach to the results. Before presenting the results of this research, the most common methods used for the interpretation of BE tests are discussed.

\section{Interpretation of Bender Elements Tests}

The attraction of the BE technique is its apparent simplicity, both in respect to the test itself and to the interpretation of the results. Many authors have dealt with the difficulties of interpretation of results (Viggiani and Atkinson 1995; Brignoli et al. 1996; Jovičić et al. 1996; Arulnathan et al. 1998; Greening et al. 2003; Greening and Nash 2004; Leong et al. 2005). In essence, it is clear from all of these authors that the interpretation of the results remains subjective, requiring some degree of judgment, and no single ideal method of interpretation has been accepted.

A BE test consists of the application of an input voltage function of defined shape and frequency to the transmitter to generate a shear wave, the propagation of this wave through the soil specimen, and the sensing of the arrival of this wave by the receiver, resulting in an output signal. The output signal is attenuated, and distorted; it is more complex than the input signal. Figure 1 illustrates this behavior, which is observed both in experimental and in numerical results (Rio 2006).

Several researchers have demonstrated a number of potential (inherent and induced) sources of error involved in BE testing and interpretation: near-field effects (Sánchez-Salinero et al. 1986, Mancuso et al., 1989; Viggiani and Atkinson 1995; Jovičić et al. 1996; Pennington 1999), wave interferences at the rigid boundaries (Arulnathan et al. 1998), specimen geometry (Arroyo et al. 2002; Hardy et al. 2002; Rio et al. 2003; Rio 2006), transducer resonance and overshooting (Jovičić 2004; Lee and Santamarina 2005), and electrical noise and grounding/shielding issues (Brignoli et al., 1996; Lee and Santamarina 2005).

In order to avoid some of these errors, it is firstly recommended to comply with a number of technical requirements and boundary conditions (Jovičić 2004; Lee and Santamarina 2005). These requirements include good electronic equipment, good shielding and grounding, properly connected and encased transducers, leak-free connections, and a noise-free environment. Other factors also play a part, especially spatial conditions, such as alignment of the BE, reflections of the wave from the edges and sides of the specimen, relative distance between transmitter and receiver; poor contact between the BEs and the soil resulting in poor coupling especially at low confining pressures; and overshooting, since at high frequencies the BE changes its predominant mode shape and the response becomes complex.

For interpretation of the received signals, diverse methodologies have been proposed over the years, ranging from the simplest method based on the immediate observation of the wave traces and measurement of the time interval between starting points, to more elaborate techniques, supported by signal processing and spectrum analyses tools. Alternative options for the selection of the input wave configuration have also been proposed, not only in terms of its shape (Table 1), but also in its frequency, with obvious impact in terms of output clarity and ease of interpretation.

Most early studies using BEs used a single square-wave pulse. However, sine-wave pulses have become more popular, as these have been shown to give more reliable time measurements, primarily (Blewett et al. 2000). The square-shaped input signal is the least favorable shape and the distorted sine wave the most favorable, as experimentally observed by Jovičić et al. (1996).

The most common methodologies for interpreting BE results are generally grouped into time-domain (TD) and in the frequencydomain (FD) methods. A short description of the main principles and applications of each method follows.

\section{First Direct Arrival of the Output Wave}

The direct measurement of the time interval between the input and output waves is the most immediate and intuitive interpretation technique, similar to the method used in in situ geophysical testing (Abbiss 1981; Dyvik and Madshus 1985; Jamiolkowski et al. 1995; Jovičić et al. 1996; Pennington 1999). This method assumes plane wave-fronts and the absence of any reflected or refracted waves (Arulnathan et al. 1998). Figure 2 shows an example of a typical sine-wave input pulse (OABC) and the resulting output signal. The identification of the instant of first inflection of the output wave is simple but subjective, as indicated by the multiple "arrow" indicators around $\mathrm{O}^{\prime}$ in Fig. 2.

\section{Time Interval Between Characteristic Points of the Input and Output Waves}

Characteristic points of the input and output waves, such as peaks, troughs, and zero intercepts, are easy to identify, and the intervals between corresponding points ( $\mathrm{AA}^{\prime}$ and $\mathrm{BB}^{\prime}$ in Fig. 2) can be con- 
TABLE 1-Input wave shape suggested by different authors.

\begin{tabular}{|c|c|c|}
\hline Input wave shape & & Reference \\
\hline & Square or step signal & $\begin{array}{l}\text { Dyvik and Madshus (1985); Fam and } \\
\text { Santamarina (1995) }\end{array}$ \\
\hline$\perp$ & Impulse signal & Lee and Santamarina (2005) \\
\hline & Sine wave & $\begin{array}{l}\text { Viggiani and Atkinson (1995); } \\
\text { Brignoli et al. (1996) }\end{array}$ \\
\hline & Sine pulse $\left[90^{\circ}\right.$ phase shift $]$ & Pennington et al. (2001) \\
\hline & $\begin{array}{l}\text { Distorted sine wave } \\
\text { [typically } 30^{\circ} \text { phase shift] }\end{array}$ & Jovicic et al. (1996) \\
\hline MHO & $\begin{array}{l}\text { Forced oscillation [sine wave cycles at } \\
\text { resonance frequency] }\end{array}$ & Jovicic et al. (1996) \\
\hline WhAnADA & $\begin{array}{l}\text { Continuous sine wave of constant } \\
\text { frequency }\end{array}$ & Greening and Nash (2004) \\
\hline 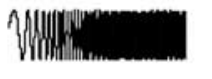 & $\begin{array}{l}\text { Sine sweep of frequencies [typically } \\
100 \mathrm{~Hz} \text { to } 20 \mathrm{kHz} \text { ] }\end{array}$ & Greening and Nash (2004); Ferreira et al. (2006) \\
\hline random signal & Stochastic random noise & Roesler (1979); Santos et al. (2007) \\
\hline
\end{tabular}

sidered to represent the travel time of the shear wave, again under the assumption of plane wave propagation and absence of reflections or refractions (Viggiani and Atkinson 1995; Arulnathan et al. 1998). However, given the material damping, attenuation, and different frequency content of the signals, successive intervals $\mathrm{AA}^{\prime}$ and $\mathrm{BB}^{\prime}$ are not identical, with later intervals tending to be greater than early ones, so the use of this method is not recommended.

\section{Cross-Correlation of the Input and Output Signals}

Based on the same assumptions as above, Viggiani and Atkinson (1995) suggested the use of the cross-correlation function, which is a measure of the degree of correlation of two signals. The crosscorrelation of a single-frequency input pulse with its response produces a peak at a time shift that is taken as the wave travel time between the two points (Mohsin and Airey 2003; Airey et al. 2003). Such a technique is strictly applicable for signals of the same nature, requiring the frequencies of both waves to be of the same magnitude (Santamarina and Fam, 1997; Jovičić et al. 1996). However, it is not clear what, if any, is the advantage in using crosscorrelation for matching a single-pulse input signal and a more complex output signal, such as the example shown in Fig. 2.

\section{Second Arrival of the Output Wave}

Arulnathan et al. (1998) observed that the transmitted wave propagates along the specimen and is reflected at the receiver platen (first arrival), propagating in the opposite direction back to the transmitter platen, where it is reflected again, and then returns to the receiver a second time. The time between first and second arrival of the wave corresponds to twice the travel time. The second arrival of the wave obviously contains less energy than the first; hence, it is often undetected in the signal, though further amplification of the output signal may be useful in this regard. Overall, the technique works only for certain combinations of travel distance, soil proper- ties, and boundary characteristics. Thus, it is easier to observe second-wave arrivals in BE tests in the oedometer than in standard triaxial tests.

Lee and Santamarina (2005) also used a method based on second arrival of the output wave (multiple reflections method). They developed a systematic approach to interpreting the results based on separating the two events of wave arrival and using the peak of the cross-correlation between the two events as the travel time for twice the plate-to-plate distance. Since the two events are measured with the same transducer, all the peripheral effects of the system are cancelled, and hence this method is very robust; however, second arrivals are often undetected.

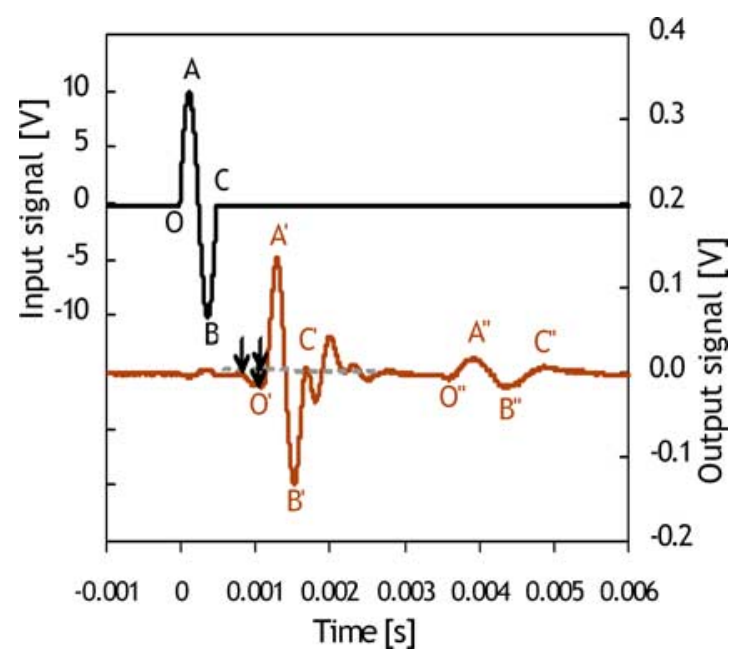

FIG. 2-Example of time domain methods: first direct arrival; interval between characteristic points; second arrival; multiple reflections. 


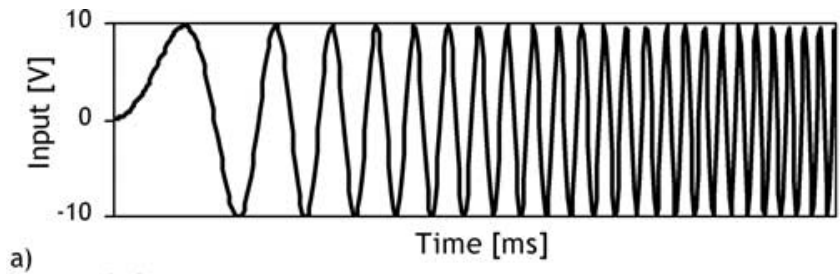

a)

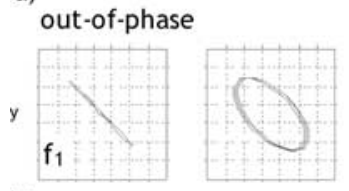

b)

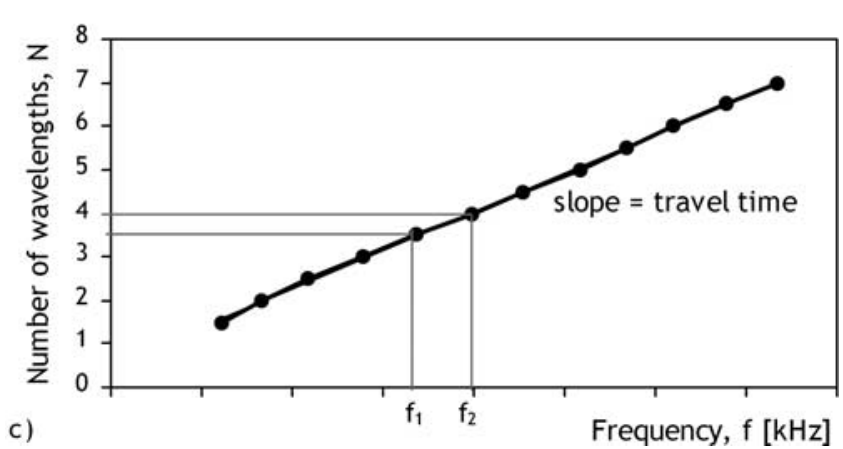

FIG. 3-Discrete $\pi$-points method: (a) manual sweeping of input frequency; (b) $X-Y$ plots in the oscilloscope; (c) determination of travel time.

\section{Discrete Method: $\pi$-point Identification}

The use of continuous input sine waves has been advocated by many researchers, mainly as a means to minimize distortion associated with different frequency components (Brocanelli and Rinaldi 1998; Blewett et al. 1999, 2000; Greening et al. 2003). However, it is not possible to read the wave travel time directly in the time domain (Kaarsberg 1975; Sasche and Pao 1978; ; Greening and Nash 2004). The $\pi$-point identification method uses continuous harmonic waves as input. In this method, the transmitted and received signals are observed directly on an oscilloscope, in a $\mathrm{X}-\mathrm{Y}$ plot of channels A and B (that is, time independent). The display shows Lissajous figures, which give an indication of the phase relationship between the channels: perfectly in-phase and out-ofphase correspond to positive and negative straight lines, respectively (Fig. 3(a)). Each of the frequencies producing a perfect phase shift between the signals is a $\pi$-point, or phase frequency, since the phase angle between the waves is a multiple of $\pi$ (or $-\pi)$. This technique is based on wave-propagation theory, in which velocity $(V)$ is a function of the frequency $(f)$ and the wavelength $(\lambda)$, or alternatively of the travel length $(L)$ and the corresponding change in phase angle $(\phi(f))$, as expressed by:

$$
V=\lambda f=2 \pi f \frac{L}{\phi(f)}
$$

Plotting the phase frequencies against the respective phase angles results in an approximately linear relationship, the slope of which is proportional to the travel time. For practical reasons, it is more convenient to use the parameter $N$ (the number of wavelengths) in the graph, as it takes multiple values of 0.5 for each phase angle multiple of $\pi$ :

$$
\begin{aligned}
& N=\frac{\phi(f)}{2 \pi} \\
& \phi(f)=k \pi
\end{aligned}
$$

from which

$$
N=\frac{k}{2}
$$

Relating $N$ with travel time results in:

$$
t=\frac{L}{V}=\frac{N}{f}
$$

The slope of the plot (Fig. 3(b)) directly provides the travel time of the wave along the specimen. This approach is more objective, but it requires manual sweeping of the input frequency to allow the $\pi$-points to be determined. As a result, this method is time consuming and enables only a limited number of points to be obtained, and thus its applicability is limited.

\section{Continuous Method: Frequency Spectral Analysis or Sweep Method}

The information provided by the discrete method could be established less onerously using an automated frequency sweep as input signal and a spectrum analyzer. The continuous sweep input method enables the acquisition of the phase angle versus frequency relationship (Greening et al. 2003; Greening and Nash 2004). These authors suggested a low-cost setup, consisting of a spectrum analyzer system loaded into a PC to control a high-speed dualchannel data acquisition unit. A sweep sine signal with a 0 to $20 \mathrm{kHz}$ bandwidth is used as input and the output signal can be observed in the time domain, where it is not feasible to determine a direct arrival time. The software processes this data (a few series of shots are used) and displays the coherence function and the relative phase angle (wrapped and unwrapped), from which the travel time is derived.

The coherence between the two signals (from 0 to 1 ) against input frequency serves as an indication of how well correlated are the two signals. The coherence function indicates how much of the energy in the output signal is caused by energy in the input signal (Hoffman et al. 2006). Hence, the higher the coherence, the more correlated are the signals. The plot of relative phase angle against frequency can be provided wrapped, that is, ranging from $-\pi$ to $\pi$, or unwrapped, starting at or near zero and continuously increasing. The travel time is derived directly from the slope of the best-fit straight line to the plot of unwrapped phase angle against frequency, for a selected frequency range.

A slightly nonlinear relationship between the relative phase angle and the signal frequency is generally observed, showing that the 0 to $20 \mathrm{kHz}$ range is too broad to provide reasonable results. However, it is still useful to start with this wide frequency range to provide an overview of the full coherence function as well as the complete relationship between unwrapped phase angle and frequency, which aids in making the decision on the most appropriate ranges to select for detailed analysis. Selection of a range showing high coherence is necessary to obtain low variation in the results, indicated by a high correlation coefficient of the best-fit line to the 
unwrapped phase angle versus frequency data. Finally, having decided on the most appropriate range, the travel time is determined directly from the slope of the best-fit line, and the shear wave velocity and shear modulus are automatically computed.

This continuous method is an interesting alternative, since it is automated and can be rapidly performed in conjunction with other methods. Since it requires the selection of a specific frequency range, undefined at the start and not automatically selected by the software, it is still a flexible and interactive system, where practical experience is combined effectively with the overall detailed information obtained in the process.

This method currently uses the electrical input from the function generator for frequency domain calculations. There are obvious peripheral effects, namely, the frequency response of the transmitter and of the electronics, which means that the excitation actually applied to the specimen is not necessarily exactly the same as the electrical input. The actual transfer function of the BE-specimen system is very difficult to measure, though it has been done on occasion using so-called "self-monitoring" BEs; i.e., BEs fitted with strain-gauges to monitor the actual movement of the BEs (Schultheiss 1983; Jovičić et al. 1996; Greening and Nash 2004). These studies have generally indicated a good matching between the $\mathrm{BE}$ vibration and the electrical signal, at least for a limited frequency range. The movement of the BEs can also be determined using a laser velocimeter, though this is only possible in air, where the BE acts as a free cantilever, or in a polyurethane sample (a small hole carved out of the sample enables the laser beam to reach, unobstructed, its target at the BE tip surface; Rio 2006). The results suggest that the discrepancies are greater in transient response (for pulse input signals) than in steady state (continuous input signals).

\section{Discussion of Current Methods}

The exercise of applying all these diverse interpretation methods in a single BE test can reveal significant variation in deduced travel times. Some techniques are not applicable in most cases, such as the second-arrival method or the multiple-reflections method, due to the rapid attenuation of the wave. Others are more or less elaborate representations of the same principle, as is the case of the $\pi$-point method and the continuous-sweep method (Greening and Nash 2004; Ferreira 2004).

A comparison of the results of applying the $\pi$-point method and the continuous-sweep method is provided in Fig. 4. This figure shows the unwrapped phase angle $\phi$ plotted against frequency $f$, for tests at two different effective confining stresses $(50 \mathrm{kPa}$ and $200 \mathrm{kPa}$ ) of a Toyoura sand specimen. The straight-line portion of these plots corresponds to the straight-line plot in Fig. 3 (note that $N$ and $\phi$ are related by Eq 2). These results were obtained in the context of an international benchmarking exercise (Ferreira and Viana da Fonseca 2005; Yamashita et al. 2007). This example clearly demonstrates that the results of these methods are practically the same in terms of the overall slope of the curve. However, even in this type of plot, the sweep method provides more information, and, as will be demonstrated later, more information can be extracted to clarify what part of the data should be used (Ferreira and Viana da Fonseca 2005).

The use of these techniques with different test conditions or different materials has shown different levels of reliability; moreover, the same method, applied by the same researcher in the same testing apparatus, may provide different levels of reliability in the interpretation, simply because of different soil properties (Alvarado

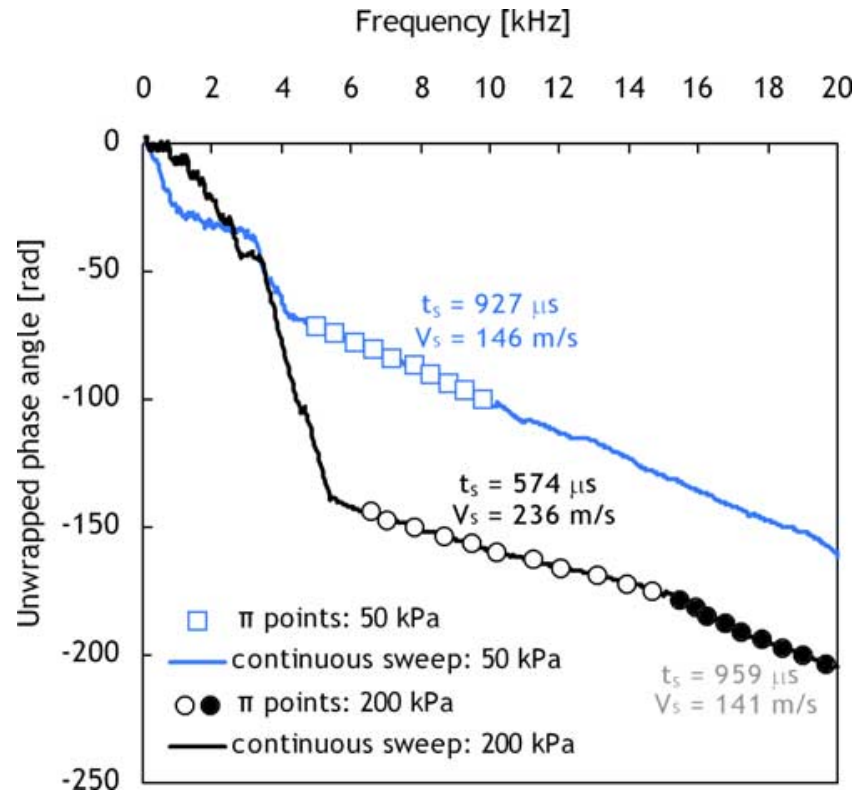

FIG. 4-Evidence of superimposed results using the $\pi$-points and sweep methods for different stress conditions (isotropic $50 \mathrm{kPa}$ and $200 \mathrm{kPa}$ ) on Toyoura sand.

and Coop 2004; Ferreira 2004; Ferreira and Viana da Fonseca 2005). The reasons for these discrepancies are not yet fully understood. The lack of consistent results represents a clear obstacle to the standardization of this technique. Therefore, there is a need to improve, alter, or even ignore some methods, while pursuing new approaches.

In current (particularly commercial) practice, automation of procedures is almost as crucial as the interpretation method itself, and hence there is a demand for automated determination of the best estimates of travel time based on different interpretation techniques. This requirement is even more relevant for the case of large testing programs, where the time required for data processing is an important factor to be taken into account. For this reason, some researchers have attempted to develop programs to automatically identify first arrivals. For example, Arroyo et al. (2003) suggested that near-field effects could be dealt with by ignoring wave amplitudes below $10 \%$ of the maximum trace amplitude, on the basis that the amplitudes produced by near-field effects are less than this limit. However, they showed that this criterion is not always applicable, as it depends on the shape of the input signal and the $L / \lambda$ ratio for the test setup. Others have been slightly more successful in achieving automation by automating frequency-domain techniques (Greening et al. 2003; Ferreira and Viana da Fonseca 2005). However, entirely automatic measurements have not yet been reported.

\section{Proposed Testing/Interpretation Framework}

The framework for BE testing proposed in this paper does not rely on a single method of interpretation of the results, but rather involves the use of a combination of methods for an enhanced interpretation, thus leading to a higher reliability in the computed travel time. The final estimate of travel time still requires an educated judgment, but in the case of BE testing, information redundancy is actually necessary in order to make an informed decision. 
The proposed framework for interpreting the BE tests is summarized as follows:

1) Apply input sine-wave pulses at various frequencies, including one resonant frequency of the specimen-BE system, and using the first-direct-arrival method to determine travel time in the time domain (TD).

2) Apply a continuous sine sweep input wave, using specific software to automatically acquire data and compute travel time in the frequency domain (FD).

In TD measurements, the resonant frequency of the system is, in general, taken to be the optimal input for a sinusoidal pulse, since this enhances the response of the BE (Lee and Santamarina 2005). This frequency can be readily determined by manually sweeping the frequency of a continuous sine input signal while observing the Lissajous response in the oscilloscope in the X-Y mode until a straight line is obtained (as for the $\pi$-points method). As the soil stiffness changes with the loading conditions, so does the resonant frequency of the system, and hence it needs to be determined at each stage of testing.

One of the complicating factors in determining the first S-wave arrival is the prior arrival of compression waves (P-waves). Therefore, complementary information from P-wave measurements, using compression transducers or bender-extender elements, is also very useful in distinguishing the arrival of the S-wave (Brignoli et al. 1996; Ferreira 2003).

In FD methods, the application of cross-spectral analysis does not require a sine sweep, but this input signal is indeed favorable, because it is an unbiased selection, has a very broad frequency spectrum, and thus has the potential of providing an almost continuous response curve from a single signal, sufficient to cover virtually any soil stiffness (Rio 2006). Frequently, this procedure is sufficient to guarantee good confidence in the estimated travel time, but this is not always the case. In fact, when the convergence of results is not immediately obtained, a more detailed analysis of the results is required. In practice, post-processing of the data is always recommended. Details are presented with practical applications below. The use of multiple methods for the analysis of BE tests has been supported by recent reports of the Technical Committee TC29 of ISSMGE (Jardine and Shibuya 2005; Yamashita et al. 2007).

\section{Application of the TD-FD Framework for Bender Element Testing}

\section{Experimental Setup}

Specimens of natural residual soil from Porto granite (Viana da Fonseca 2003; Viana da Fonseca et al. 2006) and reconstituted Toyoura sand were tested in a triaxial apparatus. The initial dimensions of the specimens were $140 \mathrm{~mm}$ height and $70 \mathrm{~mm}$ diameter (a height-to-diameter ratio, $H / D$, of 2.0). The bender elements are $10 \mathrm{~mm}$ wide, $1 \mathrm{~mm}$ thick, with a protrusion distance of $2 \mathrm{~mm}$. The setup for these tests consists of a pressure control panel, a function generator (TTi TG1010), an input-output amplifier (specifically designed by ISMES-Enel.Hydro), and an oscilloscope (Tektronix TDS 220) and/or a spectrum analyzer-oscilloscope (PicoScope ADC-216), both connected to a PC for data acquisition. This system enables not only the travel time to be measured from the dis- play of the oscilloscope, but also the signals to be transferred to a computer (PC) to further post-process the results using different approaches.

For the time-domain (TD) measurements, sine-wave input pulses were used at various preset frequencies $(1,2,4,6,8$, and $10 \mathrm{kHz}$, provided the response obtained appeared relevant) and at one of the resonant frequencies of the sample-BE system. The output signals were captured in the oscilloscope, directly transferred to the PC and plotted together. For the frequency-domain (FD) measurements, a continuous sine-sweep input wave was applied and the acquisition was carried out via the spectrum analyzer-oscilloscope using specific open-source software (Greening et al. 2003). Some modifications have been introduced to the program for postprocessing data and analysis, which are discussed below. This program is user friendly and runs in Microsoft ${ }^{\circledR}$ Excel. Acquisition is triggered by the user, and the software immediately computes the travel time, wave velocity, and shear modulus. These parameters can be recalculated for different frequency ranges. Narrower frequency ranges are then selected for computing travel time, mainly based on the results of the coherence function (further details provided below).

\section{Tests on Residual Soil from Porto Granite}

Residual soil from Porto granite is a well-studied geomaterial (Viana da Fonseca 2003; Viana da Fonseca et al. 2006). The typical Porto granite is a leucocratic alkaline rock, with two micas and medium-to-coarse grain size. The resulting residual soil is characterized by the presence of a bonded structure and fabric, which has significant influence on its engineering behavior, particularly in its small-strain stiffness properties. It has a wide grain-size distribution, with a $\mathrm{D}_{50}$ of $0.2 \mathrm{~mm}$ and a uniformity coefficient of 90 . It is usually classified as silty (SM) or well graded (SW) sand, or more rarely as clayey sand (SC) (ASTM D2487-85). The presence of fines $(\sim 40 \%<75 \mu \mathrm{m}$ and $\sim 8 \%<2 \mu \mathrm{m})$ and the relatively high void ratio (in situ values ranging from 0.6 to 0.9 ) of this soil result

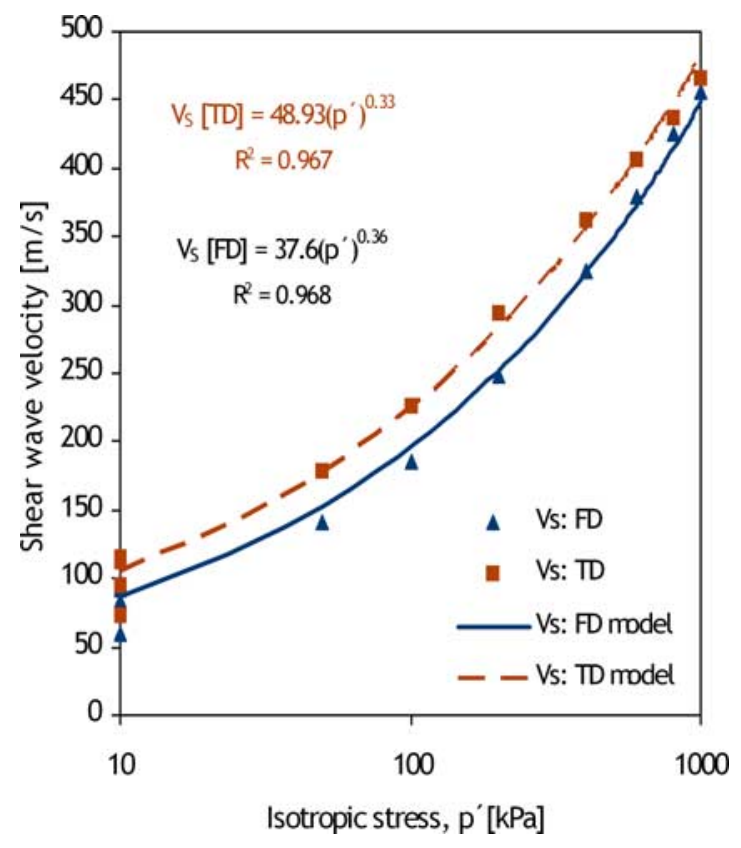

FIG. 5-Variation of shear wave velocity with isotropic consolidation stress on Porto residual soil $(w=30 \%)$ 

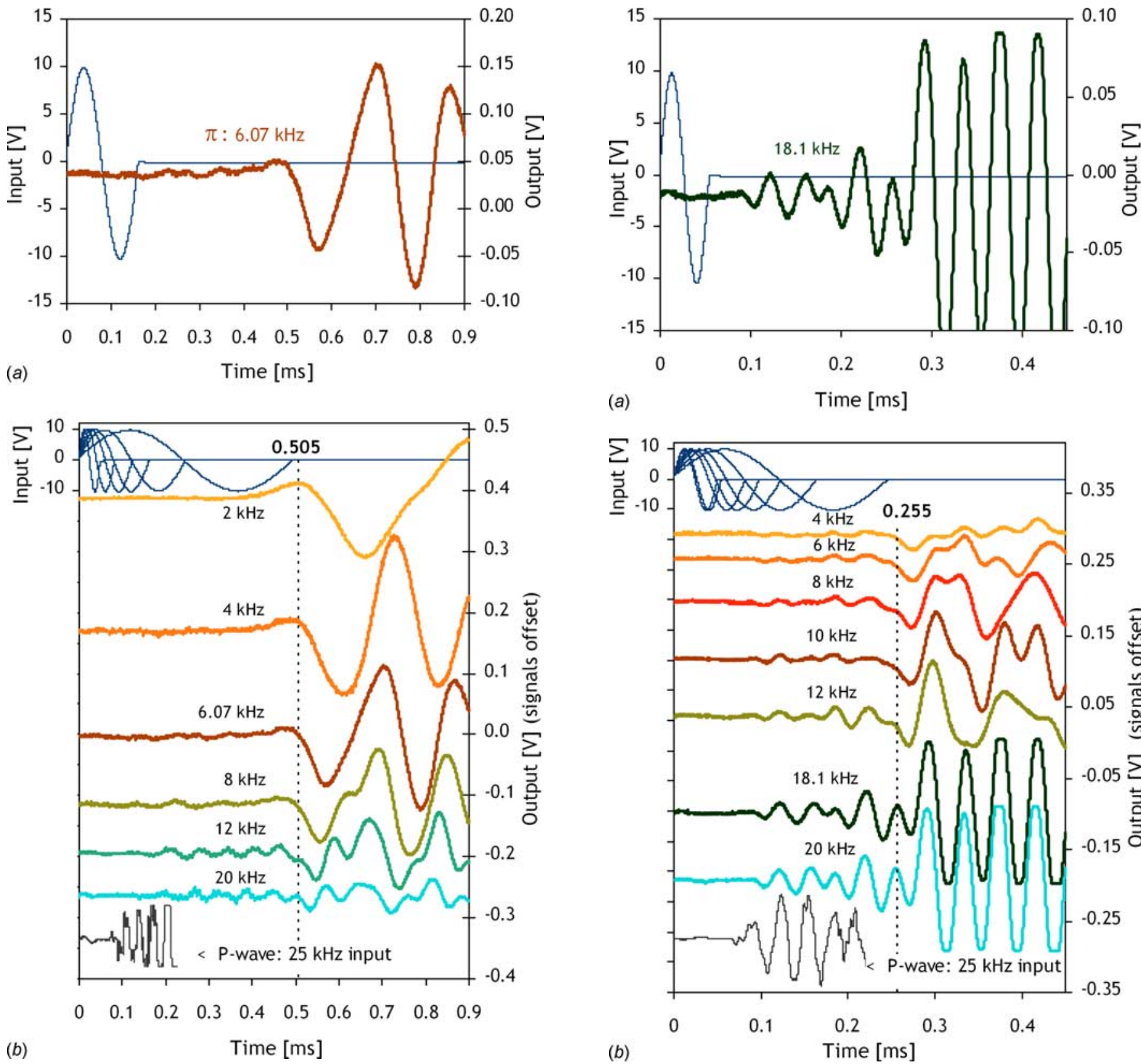

FIG. 6-TD results for input sine waves for the residual soil ( $\left.p^{\prime}=100 \mathrm{kPa}\right)$ : (a) at resonant frequency of $6.07 \mathrm{kHz}$; (b) 2, 4, 6.07, 8, 12, $20 \mathrm{kHz}$ and $P$-wave result for $25 \mathrm{kHz}$ input.

in high compressibility and high permeability $\left(k=10^{-6} \mathrm{~m} / \mathrm{s}\right.$ to $10^{-5} \mathrm{~m} / \mathrm{s}$ ).

For this case study, an isotropic consolidation test was performed on a remoulded residual soil (RS) specimen with an initial water content of $30 \%$. The soil was spooned into the sample mould and set up on the triaxial base. The top cap is then attached in the usual way. At this water content, the BEs penetrated into the sample without any difficulty. The test comprised an initial preconsolidation at $10 \mathrm{kPa}$, saturation by increments up to a backpressure of $300 \mathrm{kPa}$ (corresponding to parameter $B=1.00$ and $V_{P}$ $=1545 \mathrm{~m} / \mathrm{s}$, measured by P-wave transducers), and drained isotropic consolidation at 50,100, 200, 400, 600, 800, and $1000 \mathrm{kPa}$. The variation of shear wave velocity with isotropic confinement for the two methods (TD and FD) is presented in Fig. 5. The two methods

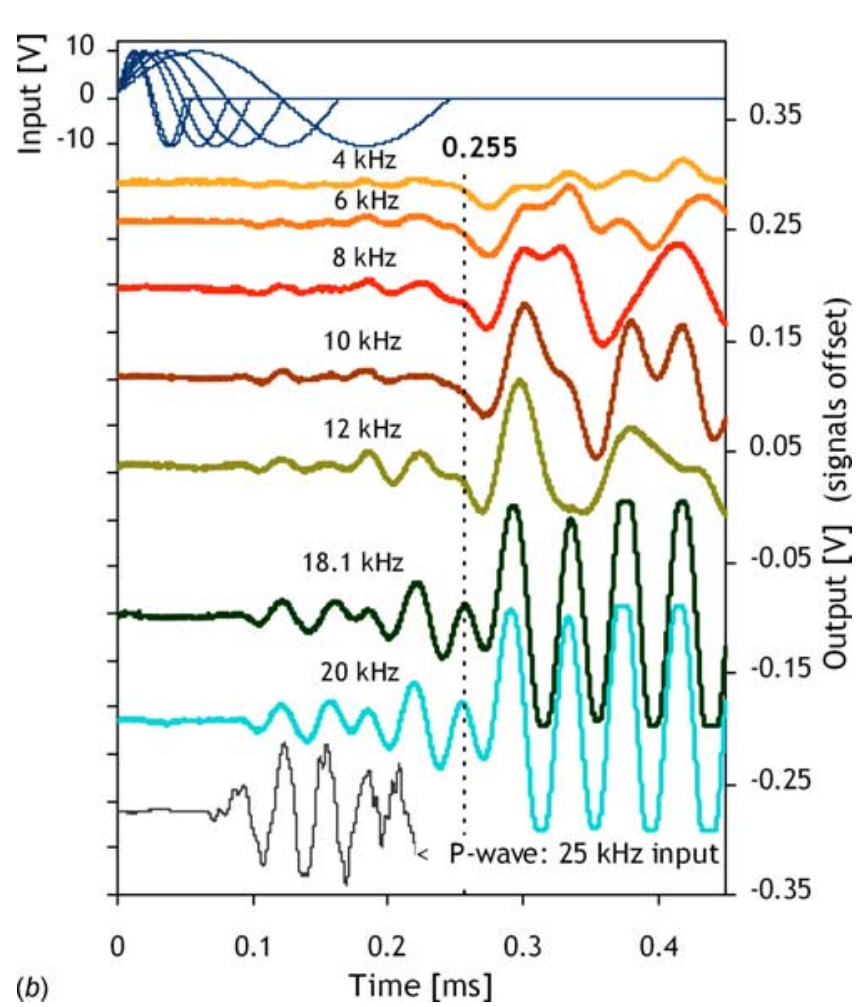

FIG. 7-TD results for input sine waves for the residual soil $\left(p^{\prime}=800 \mathrm{kPa}\right):(a)$ at resonant frequency of $18.1 \mathrm{kHz}$; (b) 4, 6, 8, 10,12, 18.1, $20 \mathrm{kHz}$ and $P$-wave result for $25 \mathrm{kHz}$ input.

produced similar results, but with the frequency-domain method (FD) giving consistently lower $V_{S}$ values. The maximum observed difference is less than $20 \%$ in wave velocity, which is not negligible. Identical conclusions were reported by Greening and Nash (2004), and therefore this appears to be a systematic difference. The reasons for such a systematic difference are not yet understood, though Arroyo et al. (2003) suggest that the TD methods are more likely than FD methods to give overestimates of $V_{s}$ due to interference from near-field effects.

For the purpose of comparison, tests at two distinct stages of the isotropic consolidation have been chosen $(p,=100 \mathrm{kPa}$ and $p$, $=800 \mathrm{kPa}$ ). The input and output signals for these two tests are shown in Figs. 6 and 7, respectively. The ratio of sample length to wavelength $(L / \lambda)$ varies between 1 and 10 for frequencies between 

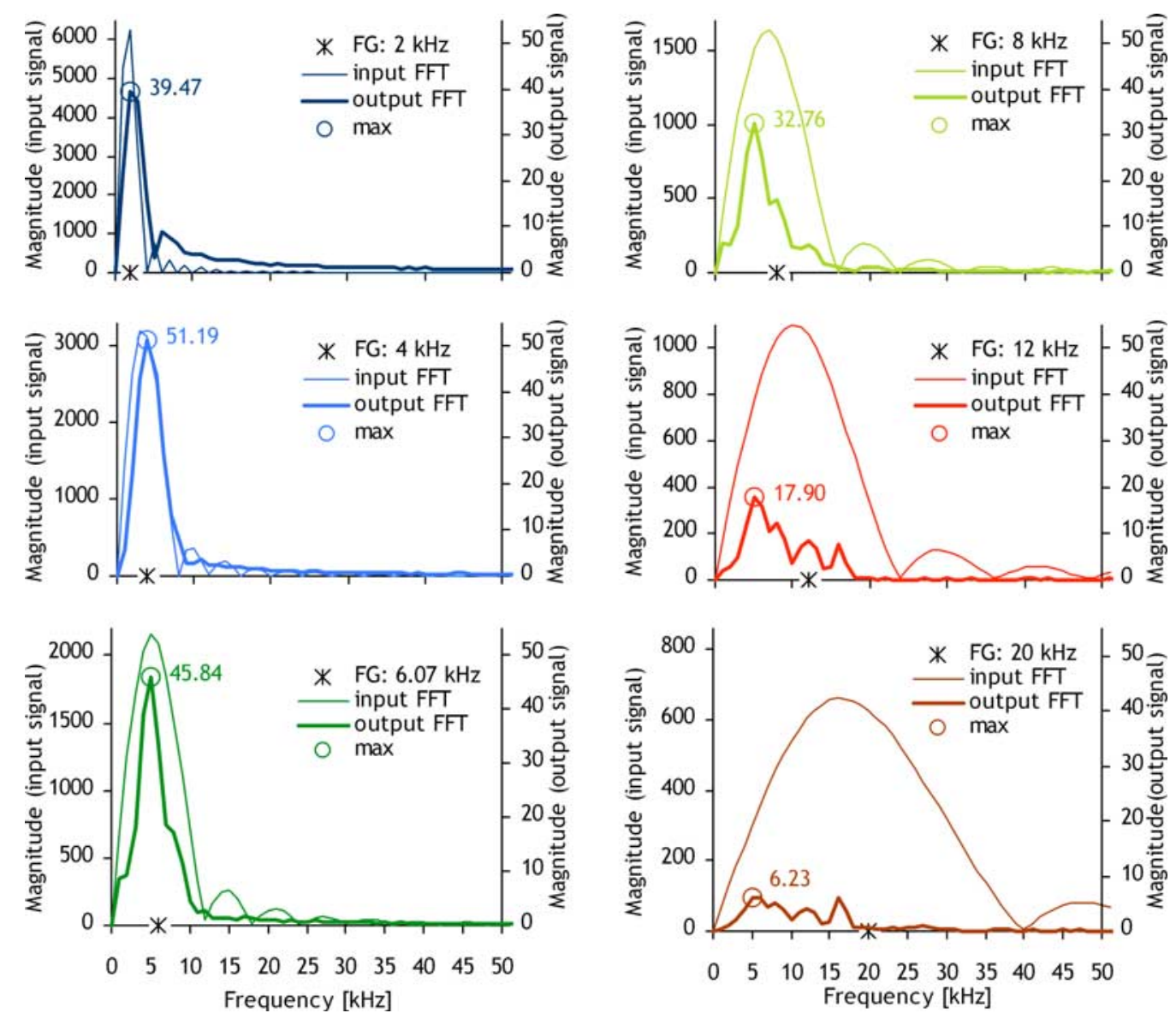

FIG. 8-Fourier transforms of the TD results presented in Fig. 6 for input sine waves for the residual soil $\left(p^{\prime}=100 \mathrm{kPa}\right)$.

$1 \mathrm{kHz}$ and $20 \mathrm{kHz}$, for the first case, and between 1 and 5 for the second case. For the lower frequencies used here, the $L / \lambda$ ratio is smaller than the minimum value (3.0) required to avoid near-field effects (e.g., Arroyo et al. 2006). Nevertheless, there is still considerable benefit to be derived within the presented framework in considering these lower frequencies, as the information provided allows an appreciation of the complete response.

Figure $6(a)$ indicates that at $p,=100 \mathrm{kPa}$, the determination of the direct travel time is quite straightforward; however, Fig. 7(a) indicates that at high stresses $(p \prime=800 \mathrm{kPa})$, interpretation is ambiguous. Both correspond to responses to a single sine input wave at resonant frequencies of $6.07 \mathrm{kHz}$ and $18.1 \mathrm{kHz}$, respectively. It should be noted that these resonant frequencies have been obtained for the full system under continuous signals (steady state). However, as previously discussed, the actual frequencies of the pulses at the input and output ends of the specimen are not necessarily identical to those of the corresponding electrical pulses because of the inherent response characteristics of the transducers. In the example, for the results at higher confining stress, the signal can be visually divided into three parts and it is unclear which part corresponds to the arrival of the shear wave. Hence, interpretation of this result requires complementary analysis - for example, by comparing the response for other input frequencies. Thus, Figs. 6(b) and $7(b)$ show superimposed results from different frequencies for the $p^{\prime}=100 \mathrm{kPa}$ and $p{ }^{\prime}=800 \mathrm{kPa}$ cases, respectively. In each case, while the resonant frequencies produced the maximum response signal of the system, lower frequencies assist favorably in the selection of the location of the shear wave arrival, which is refined with the sharper response of higher frequencies.
As previously mentioned, it is also helpful to have independent $\mathrm{P}$-wave travel-time information (from $\mathrm{P}$-wave tests carried out on the same specimen), to enable $\mathrm{P}$-wave components of the $\mathrm{BE}$ signals to be more easily differentiated from S-wave components (included in Figs. 6(b) and 7(b)).

The proposed approach is easy and quick to perform (not much more time required than for a single frequency). It is often possible to acquire more than one resonant frequency, which can be advantageous. For example, the results presented later in Fig. 10(a) show that the response of the system is maximum at two main frequencies, which are likely to be related to resonant frequencies. As previously described, finding those frequencies is a relatively simple and rapid process and applying them as additional input pulses for TD domain testing is favorable, since the amplitude of the resulting output signal will be at its highest.

Finally, it is important to display all readings in the same graph, perhaps with a vertical offset to ease readability and interpretation, as illustrated in Figs. 6 and 7. As shown in this example, the measurement of shear waves at high confinement stresses and in saturated conditions is frequently more difficult, as the difference between the travel times of the two waves narrows, for several reasons:

- $V_{P}$ remains nearly constant (around $1500 \mathrm{~m} / \mathrm{s}$ to $2000 \mathrm{~m} / \mathrm{s}$ ), while $V_{S}$ increases significantly with increasing confining stress, such that the P-wave effects are still present when the first $\mathrm{S}$-wave arrival occurs (in this case, the $V_{P} / V_{S}$ ratio at $100 \mathrm{kPa}$ is 7.45 , while at $800 \mathrm{kPa}$ it is 4.25 );

- the amplitude of the P-wave response is much higher after 

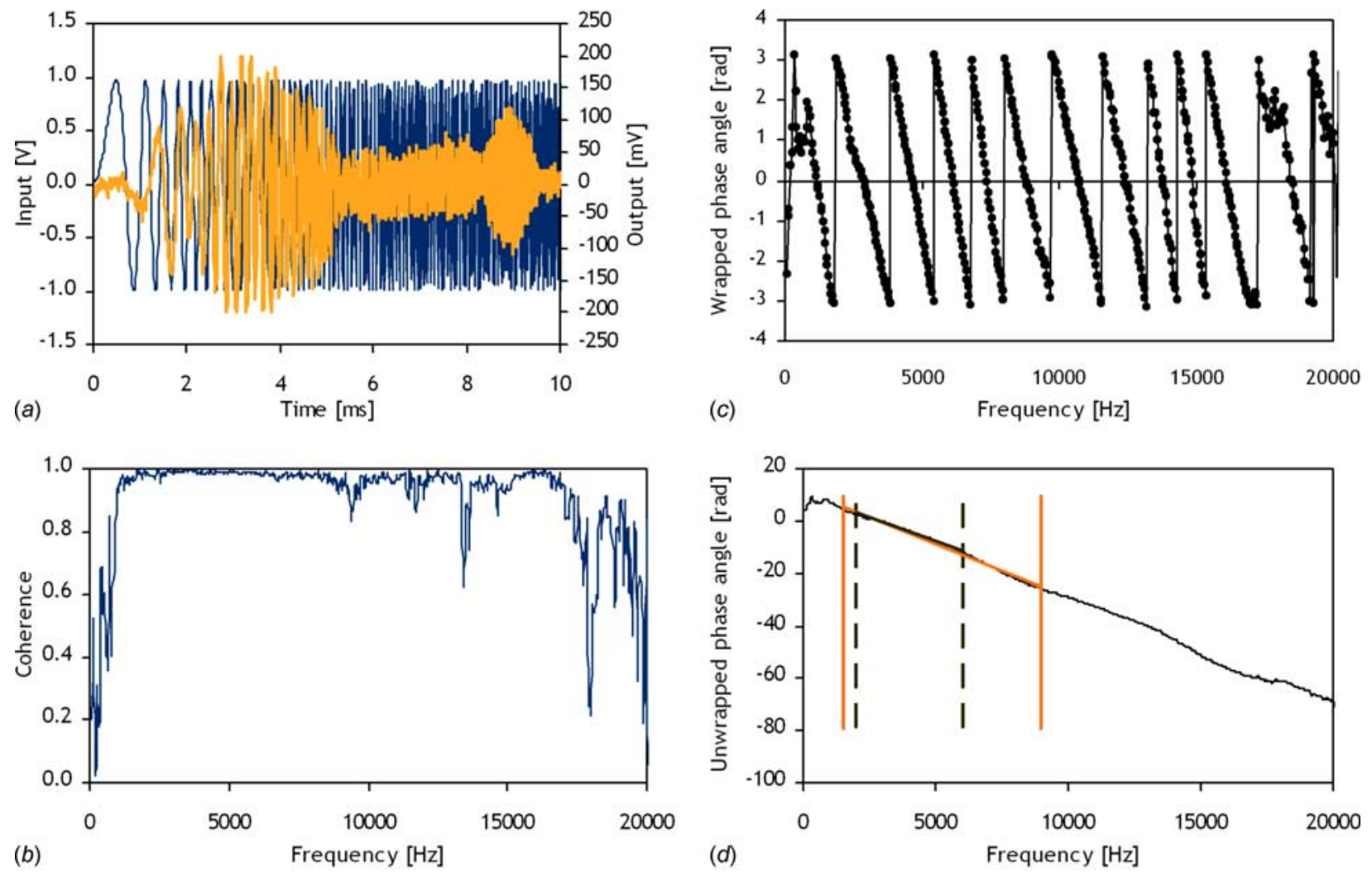

(d) $\quad$ Frequency $[\mathrm{Hz}]$

\begin{tabular}{|c|c|c|c|c|c|c|}
\hline $\begin{array}{l}\text { Frequency } \\
\text { ranges }\end{array}$ & $\begin{array}{c}\mathrm{f1} \\
{[\mathrm{Hz}]}\end{array}$ & $\begin{array}{c}\mathrm{f} 2 \\
{[\mathrm{~Hz}]}\end{array}$ & $\begin{array}{c}\text { travel time } \\
\text { [ms] }\end{array}$ & $\begin{array}{l}\text { correlation } \\
\text { coefficient }\end{array}$ & $\begin{array}{c}\text { wave velocity, } \mathrm{V}_{\mathrm{s}} \\
{[\mathrm{m} / \mathrm{s}]}\end{array}$ & $\begin{array}{c}\text { modulus estimate, } \mathrm{G}_{0} \\
{[\mathrm{MPa}]}\end{array}$ \\
\hline$\longrightarrow$ & 1500 & 9000 & 0.6577 & 0. 9915 & 182.5 & 64.9 \\
\hline--- & 2000 & 6000 & 0.5664 & 0. 9945 & 211.9 & 87.5 \\
\hline
\end{tabular}

FIG. 9-FD results for the residual soil ( $p^{\prime}=100 \mathrm{kPa}$ ): (a) input and output signals in timescale; (b) coherence; (c) wrapped, and (d) unwrapped phase angle against frequency; (e) summary of results.

saturation, and may even approach the amplitude of the $\mathrm{S}$-wave response, making it difficult to separate them in the received signal;

- the input frequency for BEs is limited (usually to $20 \mathrm{kHz}$ ), due to the characteristics of the transducers, filters, and amplifiers and the resolution of the acquisition system, and hence it may not be possible to apply sufficiently high input frequencies to cover a wider range for higher confining stresses.

Complementarily, the frequency content of each of these signals can be computed using a fast Fourier transform function, and analyzed by comparison with the imposed input frequency. In essence, this function numerically decomposes or separates the signal into a series of different continuous sinusoidal functions which sum to the original waveform, as proposed by Cooley and Tukey (1965). To illustrate this method, the Fourier transforms (FTs) of the TD results presented in Fig. 6 for the residual soil at a low confinement stress $(p \prime=100 \mathrm{kPa})$ are provided in Fig. 8. Ideally, the transforms should be calculated using a wide time window adjusted to fit the complete waveform. In the present case, the chosen time frame is shorter to provide greater resolution around first arrival, as required by TD methods. Since these transforms were computed using exactly the same signals in Fig. 6, which are incomplete for almost all input frequencies due to the short time windows, there may be some inaccuracies in its interpretation. For this reason, the conclusions to be drawn are limited yet indicative.

The Fourier spectra in Fig. 8 clearly show that the participation of spurious frequencies is reduced in the BE response, as the output frequency content is well contained within the input FT curve. The magnitude of the response is maximum around $4 \mathrm{kHz}$ to $6 \mathrm{kHz}$, and rapidly decreases with the increase of the input frequency. The spectra also show that even when high frequencies, such as $12 \mathrm{kHz}$ and $20 \mathrm{kHz}$, are used as input signals, the response is governed by what appears to be the resonance of the system around $5 \mathrm{kHz}$. This confirms the weakness of using high input frequencies in the present test, at which the BE are unable to provide a proper and clear response, as if these frequencies were being filtered.

Similar conclusions can be drawn from the FT of the signals in Fig. 7, which is not reproduced herein. The use of high frequencies at higher confinement stresses (of Fig. 7) may be counterproductive not only because of the higher level of confinement, which reduces the response of the BE thus producing a higher noise level, but also 

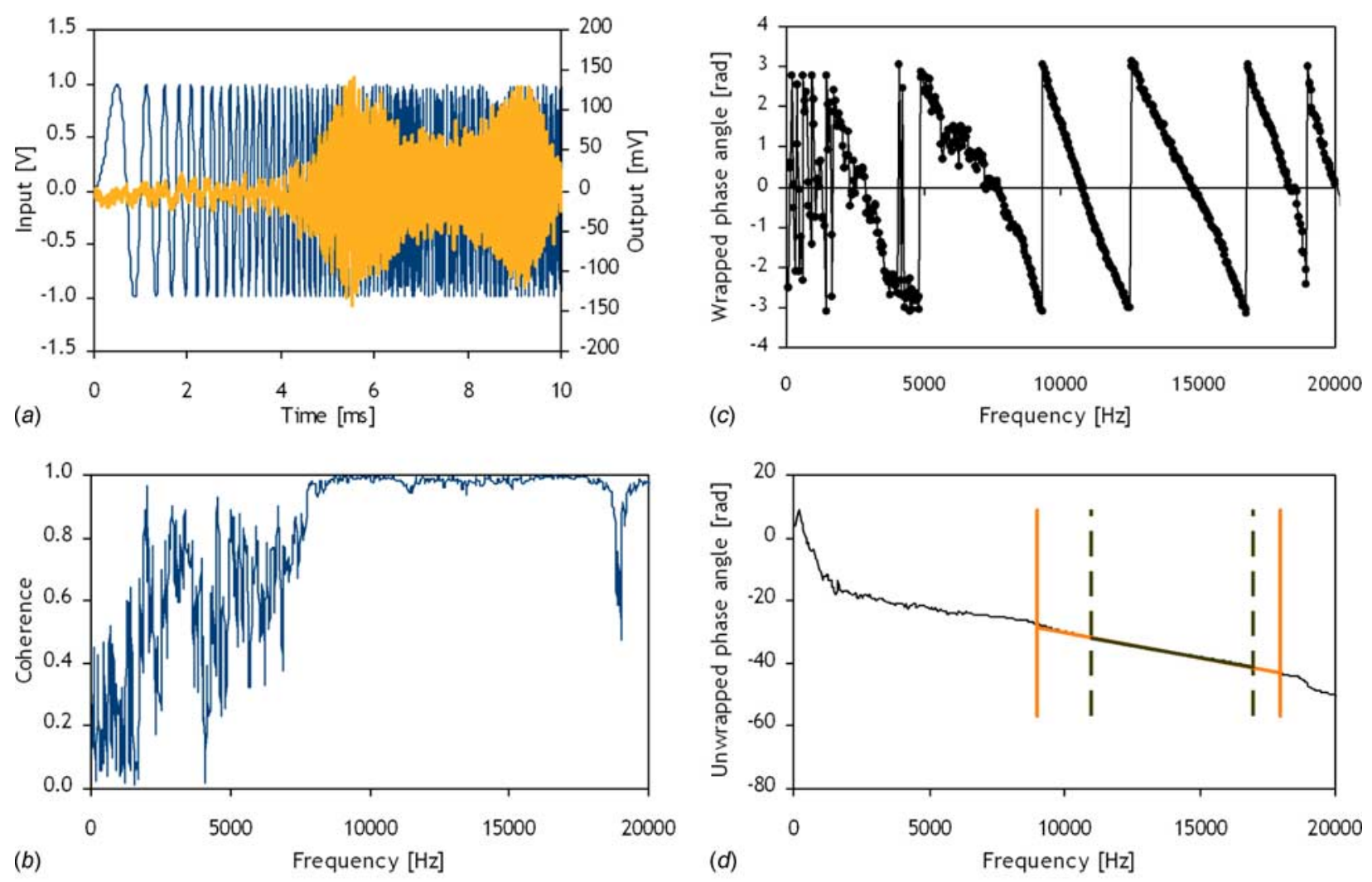

\begin{tabular}{ccccccc}
\hline $\begin{array}{c}\text { Frequency } \\
\text { ranges }\end{array}$ & $\begin{array}{c}\mathrm{f1} \\
{[\mathrm{Hz}]}\end{array}$ & $\begin{array}{c}\mathrm{f2} \\
{[\mathrm{Hz}]}\end{array}$ & $\begin{array}{c}\text { travel time } \\
{[\mathrm{ms}]}\end{array}$ & $\begin{array}{c}\text { correlation } \\
\text { coefficient }\end{array}$ & $\begin{array}{c}\text { wave velocity, } \mathrm{V}_{\mathrm{s}} \\
{[\mathrm{m} / \mathrm{s}]}\end{array}$ & $\begin{array}{c}\text { modulus estimate, } \mathrm{G}_{0} \\
{[\mathrm{MPa}]}\end{array}$ \\
\hline & 9000 & 18000 & 0.259 & 0.995 & 463.6 & 419.1 \\
--- & 11000 & 17000 & 0.235 & 0.997 & 509.8 & 506.9 \\
\hline
\end{tabular}

FIG. 10 - FD results for the residual soil $\left(p^{\prime}=800 \mathrm{kPa}\right)$ : (a) input and output signals in timescale; (b) coherence; (c) wrapped, and (d) unwrapped phase angle against frequency; (e) summary of results.

due to the risk of increasing the participation of higher modes of vibration in the response of $\mathrm{BE}$ as the specimen stiffens.

Figure $9(a)$ shows the input and output signals from a sine-wave sweep test, plotted in the time domain, for the confining stress $p$, $=100 \mathrm{kPa}$. Clearly, it is not feasible to determine the arrival time directly from a plot such as this. Figure $9(b)$ shows the graph of the coherence between the two signals (from 0 to 1 ) against input frequency. Figures $9(c)$ and $9(d)$ represent the wrapped (ranging from $-\pi$ to $\pi$ ) and the unwrapped phase angle, respectively, plotted against frequency. Frequency-domain measurements have also been made using a sweep-sine input wave in parallel with the timedomain measurements. A significant amount of information can be acquired automatically and rapidly using this approach (Greening and Nash 2004).

The travel time is derived directly from the slope of best fit to the curve in Fig. $9(d)$, for a selected range of frequencies. The coherence plot (Fig. 9(b)) is used to aid in determining the optimum frequency range. In this case, the low coherence below $1 \mathrm{kHz}$ and above $16 \mathrm{kHz}$ indicated in Fig. 9(b) suggests that noise dominates the signal outside these frequencies. Using a sweep frequency range wider than required ( 0 to $20 \mathrm{kHz}$ in this case) is useful as an overview of the full coherence function, allowing the most appro- priate to be chosen for the analysis. In this example, two frequency ranges have been selected corresponding to $1.5 \mathrm{kHz}$ to $9 \mathrm{kHz}$ and $2 \mathrm{kHz}$ to $6 \mathrm{kHz}$, indicated in Fig. $9(d)$ by the vertical solid and dashed lines, respectively. The deduced travel time, correlation coefficient, S-wave velocity, and stiffness value for each range are shown in the inset table on Fig. 9(e). Despite the high correlation coefficients for both ranges, the resulting travel times are considerably different. Similar conclusions apply to the second case ( $p$ ' $=800 \mathrm{kPa}$ ) in Fig. 10 .

Given the variability of the results, further analysis of the data should be performed to complete the process. A useful sensitivity analysis of frequency-domain measurements consists of selecting different frequency sampling ranges or windows to observe the changes in the travel time deduced with change in frequency. For this purpose, a simple Visual Basic program was implemented, to manipulate the sweep data using unbiased pre-established moving frequency windows $(0.5,1,2,4$, and $6 \mathrm{kHz})$, to continuously calculate the best-fit line and corresponding travel times for each window location. The generated curves of time versus frequency for each window, which are termed arrival-time spectra, are presented in Figs. 11 and 12, and each curve contains a marker indicating the maximum correlation coefficient (maximum value of $R^{2}$ ). The cor- 

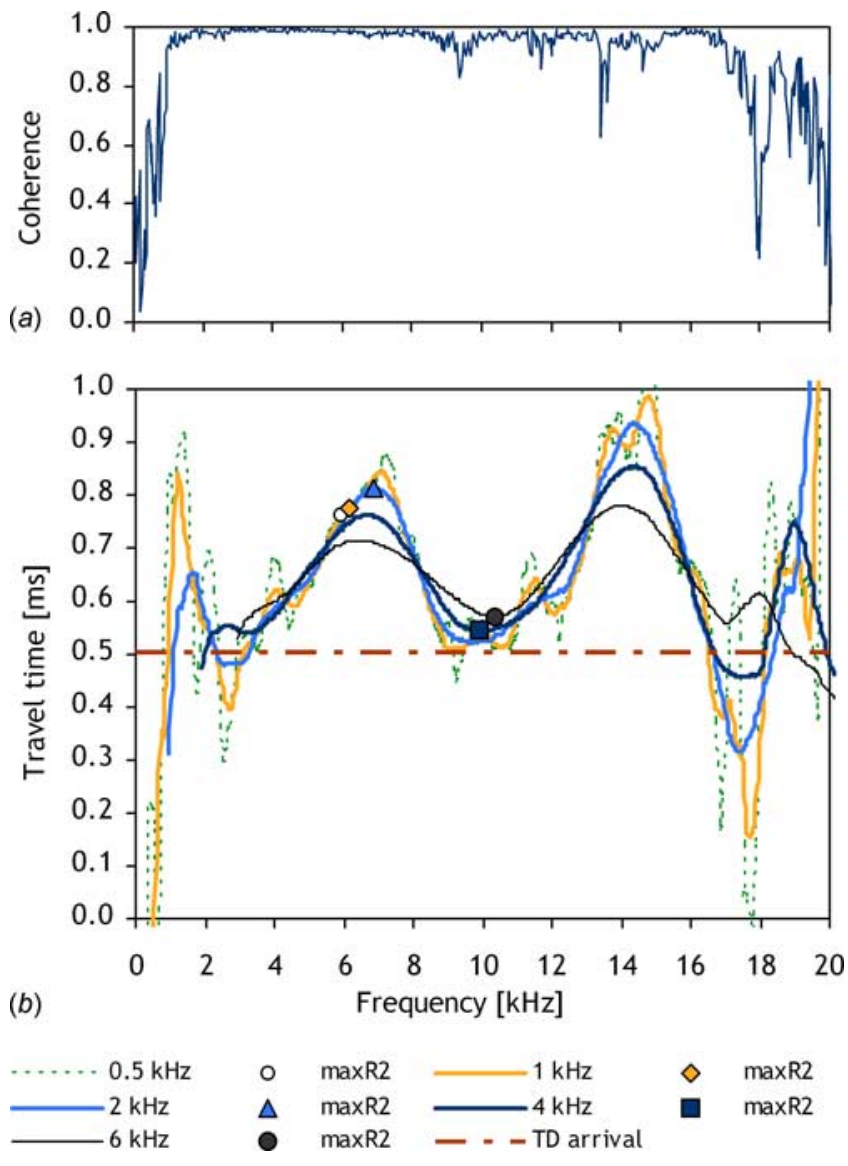

FIG. 11-FD analysis results for the residual soil $\left(p^{\prime}=100 \mathrm{kPa}\right)$ : (a) coherence for the initial window $(100 \mathrm{~Hz}-20 \mathrm{kHz})$; (b) travel-time spectra.

responding first arrival results from the TD analysis (the horizontal dashed line) are also included and the coherence plot is presented above the graph, for guidance. In general, the wider-frequency windows $(2,4$, and $6 \mathrm{kHz})$ provide lower variability, as these tend to smooth and average the results, while the arrival-time spectra for narrower windows $(0.5 \mathrm{kHz}$ and $1 \mathrm{kHz})$ are highly variable and more sensitive to noise interferences in the signal. Since these narrow-window spectra are similar to the original signal, they are almost representative of single-frequency travel times, which serve as a useful check on the validity of the other spectra. For example, for a central window frequency of $10 \mathrm{kHz}$, Fig. 11(b) shows an almost identical travel time from all windows, including the narrowest one. From this process, the selection of the arrival time is based upon the position of the markers of maximum correlation, selected automatically in the software. As in Figs. 11(b) and 12(b), knowledge of the TD arrival time helps in the final selection.

Figure 11(b) shows significant fluctuation in the arrival time between $1.5 \mathrm{kHz}$ and $9 \mathrm{kHz}$, corresponding to the high-coherence section in Fig. 11(a), and this fluctuation is not noticeable in Fig. $9(d)$. In Fig. 12(b), the arrival-time spectra again show considerable variability, despite the high coherence values from $6 \mathrm{kHz}$ tp $20 \mathrm{kHz}$ indicated in Fig. 12(a). Therefore, the initial concept of a selection based solely on coherence values close to unity is clearly not sufficient to guarantee an accurate determination of the travel time. Instead, the selection of the maximum correlation points of the arrival-time spectra, especially for higher ranges of frequency ( $4 \mathrm{kHz}$ or $6 \mathrm{kHz}$ ) appears to be more consistent. This procedure is also apparently able to overcome the limitations regarding the glo-
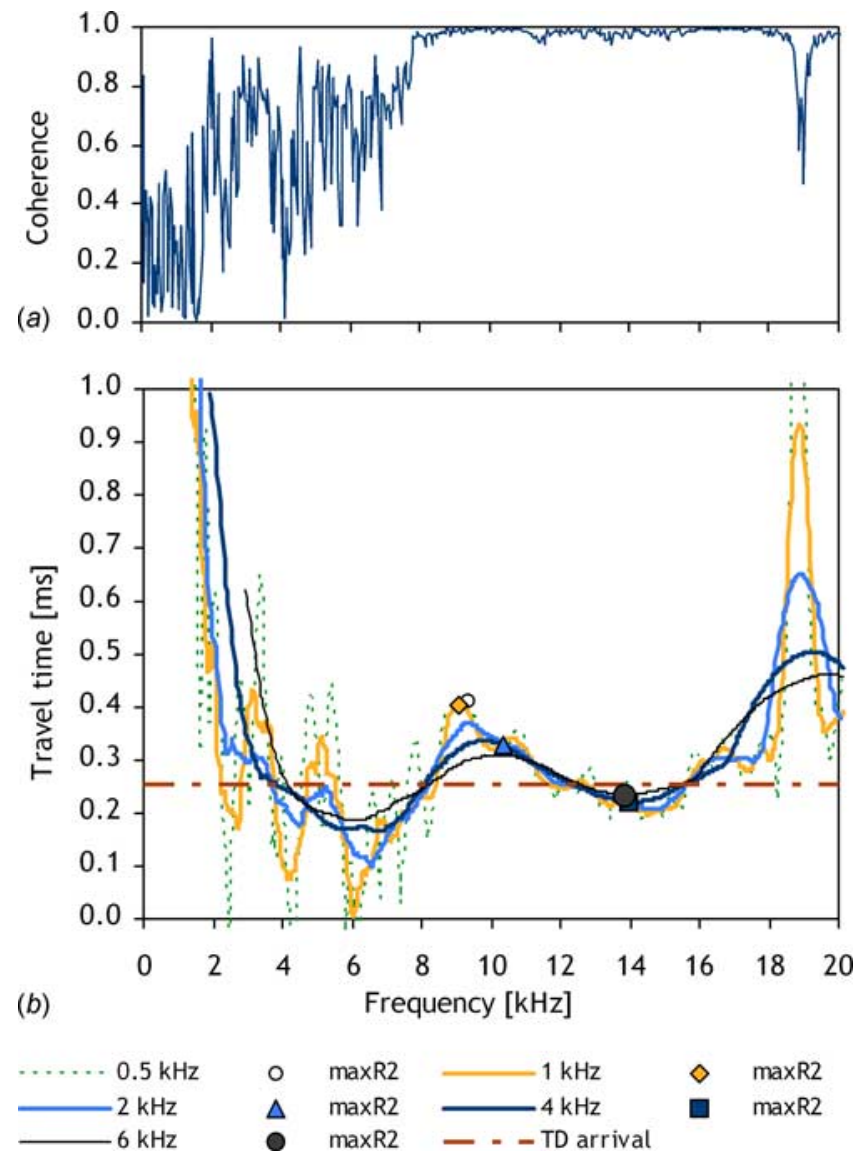

FIG. 12-FD analysis results for the residual soil $\left(p^{\prime}=800 \mathrm{kPa}\right)$ : (a) coherence for the initial window $(100 \mathrm{~Hz}-20 \mathrm{kHz})$; (b) travel-time spectra.

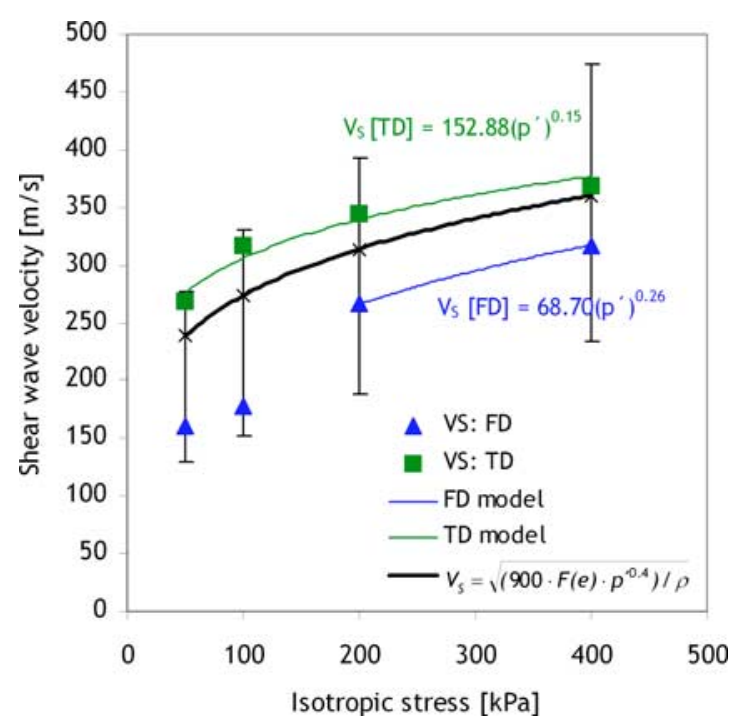

FIG. 13-Variation of shear wave velocity with isotropic consolidation stress on Toyoura sand. 

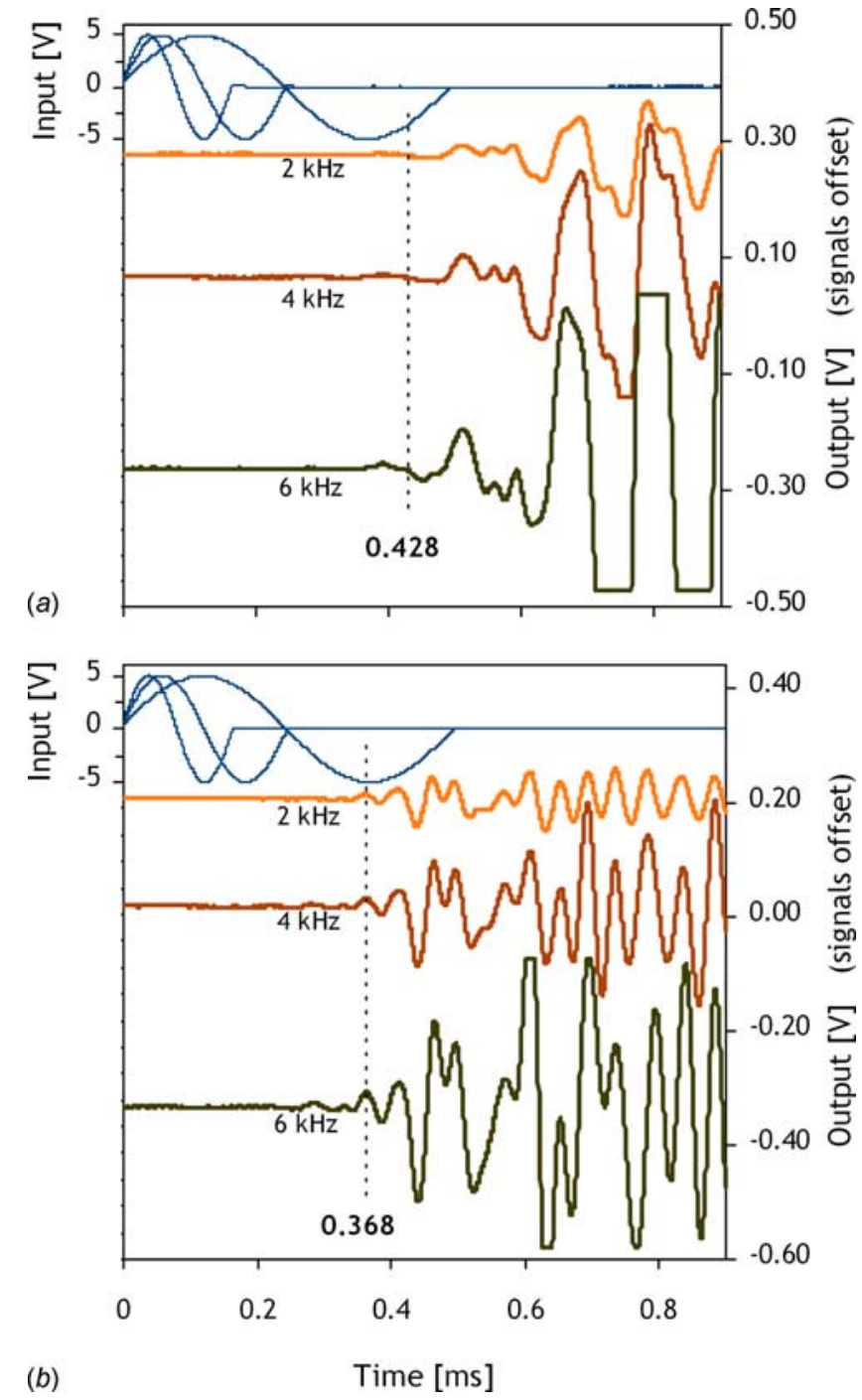

FIG. 14-TD results for input sine waves of 2, 4, $6 \mathrm{kHz}$ on Toyoura sand: (a) at $100 \mathrm{kPa}$; (b) at $400 \mathrm{kPa}$. Note: $S$-wave outputs in reversed polarity.

bal transfer function of the BE system, which are likely to be partly responsible for the variability of the travel-time spectra.

As illustrated in this section, the technique of using travel-time spectra is useful and practical for selecting the most adequate travel time, besides enabling an overview of the variation of travel time. The combination of arrival-time spectra results and TD results gives confidence in the validity of the final travel time selected.

\section{Tests on Toyoura Sand}

Analyses similar to those just described were also carried out for a series of BE measurements on a dry Toyoura sand specimen, also under isotropic consolidation conditions. The Toyoura sand is a well-known Japanese standard sand, with a $D_{50}$ of $0.17 \mathrm{~mm}$ and a uniformity coefficient of 1.6.

The specimen was air pluviated, resulting in a void ratio of 0.69 (Ferreira and Viana da Fonseca 2005). Four isotropic stress stages ( $p^{\prime}$ of $50,100,200$, and $400 \mathrm{kPa}$ ) were applied. The shear-wave velocities obtained using the time-domain approach (TD, square symbols) and frequency-domain approach (FD, triangle symbols) are plotted against the applied isotropic stress in Fig. 13. The best- fit power function to the TD results is included as a solid line, and a similar line is included for the FD results, but in this case, only the two highest-stress results are used in the fit, since the lower-stress data do not seem to fit the same trend, as discussed below.

Figure 13 also shows a relationship obtained from resonant column tests by Iwasaki and Tatsuoka (1977), which is often taken to be a reference curve for this material. This relationship was found to give a good overall fit to the average of the results obtained from the recent round-robin set of tests conducted on this soil by a number of institutions around the world (Yamashita et al. 2007). Also included on this curve are error bars, which indicate the range of the results from this exercise. This indicates that the results from the tests described here are within the range of the results from the other institutions, but with the TD results lying above the reference curve, and the FD results lying below it.

This plot indicates a significant difference between the results of the two approaches. The FD analysis gives lower values of $V_{S}$, corresponding to only $65 \%$ of $V_{S}$ obtained from the TD approach at the lowest stress. There is a significant convergence at higher stresses, which is likely associated with a higher coupling between the soil and the BE, aided by the stiffening of the soil under the higher confining stress. The FD results also show two distinct trends, one for $p$ ' of 50 and $100 \mathrm{kPa}$, and another for $p$ ' of 200 and $400 \mathrm{kPa}$. The power function fitted to the upper two points gives an exponent of 0.26 .

To illustrate the application of the full framework in this case, two stages (at $p$ ' of $100 \mathrm{kPa}$ and $400 \mathrm{kPa}$ ) are presented in detail. The TD results for these stages are shown in Figs. 14(a) and 14(b)). Unfortunately, P-wave measurements were not made in this case, so independent $\mathrm{P}$-wave arrival times cannot be shown.

Frequency-domain plots for this test are presented in Fig. 15, along with tabulated results for the $p^{\prime}=100 \mathrm{kPa}$ and $p^{\prime}$ $=400 \mathrm{kPa}$ stages. The arrival-time spectra for both stages have been generated automatically, as shown in Figs. 16 and 17. It is clearly more difficult to select a travel time for the $100 \mathrm{kPa}$ stage than for the $400 \mathrm{kPa}$ stage. For the former case, the best estimate from the arrival-time spectra approach is about $60 \%$ greater than that from the TD first-arrival approach. The fluctuations of travel time with frequency for the various frequency windows decrease substantially with stress increase, as do the differences in the travel time measured by the first-arrival method. This fact is likely to be associated with a higher coupling between the soil and the BE, aided by the densification and stiffening of the soil.

\section{Comparison of the Results of the Two Natural Soils}

Bender element testing of these two natural soils, using the same testing apparatus and identical sample dimensions and procedures, has provided significantly different levels of reliability in the results obtained via TD and FD methods. Figures 5 and 13 illustrate the variation of the shear-wave velocity with isotropic confining stress as provided by each of the methods, and clearly demonstrate greater variability and divergence in the results for the Toyoura sand compared to those from the residual soil. Additionally, the wave traces shown in Figs. 6 and 14(a) for the two specimens under the same confining stress are significantly different: the number of cycles in the output signals for the Toyoura sand specimen is much higher than for the residual soil, revealing longer reverberation time and hence lower damping.

An important factor that may be influencing the quality of the results for the Toyoura sand is that these tests were carried out in a 

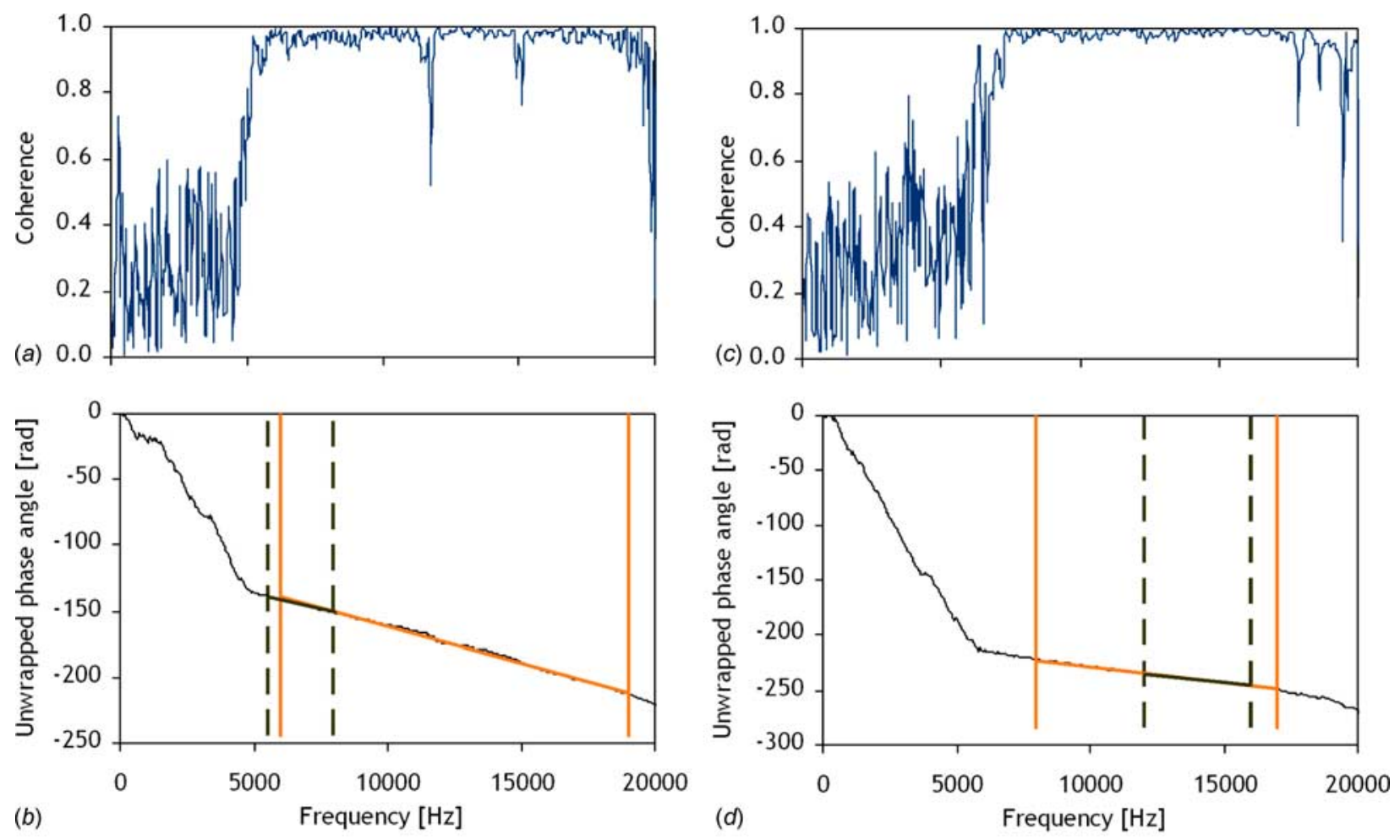

\begin{tabular}{cccccccc}
\hline $\begin{array}{c}\text { Test } \\
\text { stages }\end{array}$ & $\begin{array}{c}\text { Frequency } \\
\text { ranges }\end{array}$ & $\begin{array}{c}\mathrm{f}_{1} \\
{[\mathrm{~Hz}]}\end{array}$ & $\begin{array}{c}\mathrm{f}_{2} \\
{[\mathrm{~Hz}]}\end{array}$ & $\begin{array}{c}\text { Travel time } \\
{[\mathrm{ms}]}\end{array}$ & $\begin{array}{c}\text { Correlation } \\
\text { coefficient }\end{array}$ & $\begin{array}{c}\text { Wave velocity, } \mathrm{V}_{\mathrm{s}} \\
{[\mathrm{m} / \mathrm{s}]}\end{array}$ & $\begin{array}{c}\text { Shear modulus, } \mathrm{G}_{0} \\
{[\mathrm{MPa}]}\end{array}$ \\
\hline \multirow{2}{*}{$100 \mathrm{kPa}$} & --- & 6000 & 19000 & 0.878 & 0.996 & 153.7 & 36.4 \\
\hline \multirow{2}{*}{$400 \mathrm{kPa}$} & - & 8000 & 0.788 & 0.998 & 171.3 & 45.2 \\
\hline
\end{tabular}

(e)

FIG. 15-FD results for Toyoura sand $\left(p^{\prime}=100 \mathrm{kPa}\right)$ : (a) coherence; (b) unwrapped phase angle against frequency; Toyoura sand $\left(p^{\prime}=400 \mathrm{kPa}\right)$ : (c) coherence; (d) unwrapped phase angle against frequency; (e) summary of results.

dry condition. It has been pointed out by a number of authors (e.g., Lee and Santamarina, 2005; Arroyo et al. 2006) that side reflections of P-waves are less likely in a saturated triaxial sample than in a dry one, because the impedance difference between the saturated soil and the cell water is much smaller than between the same dry soil and cell water.

However, these different saturation conditions cannot completely account for such differences in the results, which are believed to be also related to the nature and characteristics of each soil. The mean grain size $\mathrm{D}_{50}$ of these soils is similar, but one striking difference between these soils relates to their grain-size distributions: the Toyoura sand is a uniform sand $\left(\mathrm{C}_{\mathrm{u}}=1.6\right)$, while the residual soil is a (clayey) silty sand $\left(C_{u}=90\right)$. Even though there are not enough data to establish any definite conclusion, it is plausible that a well-graded material would facilitate better wave propagation than a poorly graded material, given the continuity provided by the packing of the grains in the well-graded material. Moreover, with a well-graded material, the coupling with the BE is aided by the arrangement of the finer particles around the transducers. The lower dependence of $V_{s}$ on confining stress obtained with the residual soil specimen corroborates this hypothesis. Hence, it seems plausible that the quality of BE results, and hence the reliability in interpreting the results, depends to some extent on the degree of uniformity in the grain-size distribution.

Another important factor is that, with the much higher velocities in the Toyoura sand compared to the Porto residual soil, the $L / \lambda$ ratios were consistently lower-in the range 0.8 to 2.6 at $p$ ' $=200 \mathrm{kPa}$ and 0.7 to 2.2 at $p^{\prime}=400 \mathrm{kPa}$, for the frequency range $2 \mathrm{kHz}$ to $6 \mathrm{kHz}$. These ratios are such that near-field effects are more likely to affect the output signals, being less than the value of 3.0 suggested by Arroyo et al. (2006) as the limit above which such effects should not be present. Ideally, this would be overcome using higher frequencies, but in this case, the response at higher frequencies was too weak to allow sensible analysis.

In the discussion of dispersion effects, this issue of frequency is extremely relevant. Santamarina et al. (2001) proposed a simplified relationship for soils in a saturated condition, in the light of Biot (1956) theory of propagation of seismic waves in fluid-saturated 

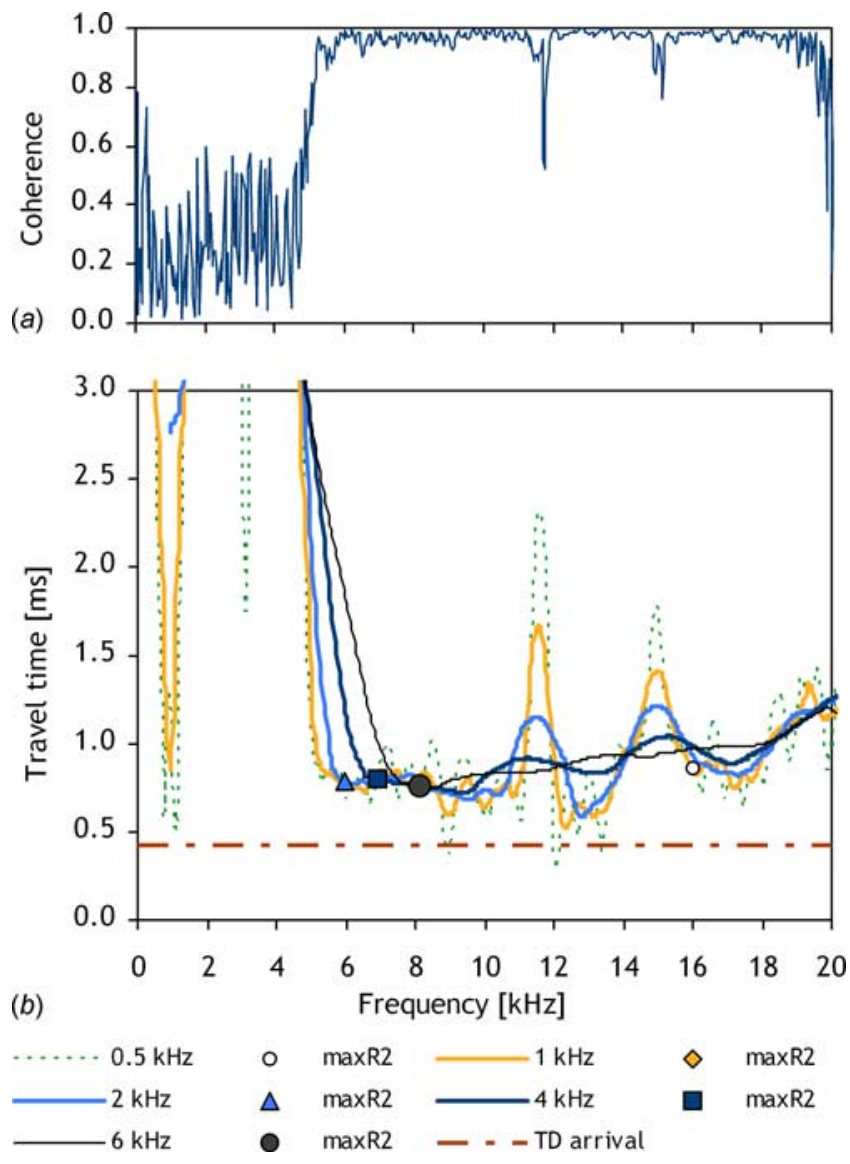

FIG. 16 -FD analysis results for Toyoura sand $\left(p^{\prime}=100 \mathrm{kPa}\right)$ : (a) coherence; (b) travel-time spectra.

porous materials, and defined the frequency threshold for dispersion (the "characteristic" frequency), directly related with porosity and hydraulic conductivity. As noted by Santamarina et al. (2001), as permeability decreases with increasing fines content (and increasing specific surface), the characteristic frequency increases and the Biot dispersion effects lose relevance. For the residual soil considered here $\left(k \sim 10^{-6} \mathrm{~m} / \mathrm{s}\right)$, the critical frequency is about $1 \mathrm{MHz}$, while for the Toyoura sand (if it were saturated), it is just of the order of $10 \mathrm{kHz}$. As a result, higher dispersion would be expected for the sand in a saturated condition than for the residual soil. On the other hand, Yamashita et al. (2007) shows a comparison between BE results on dry and saturated Toyoura sand, clearly revealing greater scatter in dry conditions, which suggests that the problem is not related to (Biot-type) dispersion. Consequently, it appears that a dry clean sand, such as the Toyoura sand used here, poses a challenge for BE testing for standard testing frequencies, while the residual soil appears to be unaffected.

In a different study, Arroyo (2001) applied Krautkrämer and Krautkrämer's (1990) experience in ultrasonic testing of materials - natural materials, composed of grains - to derive the operating frequencies above which scattering-related attenuation starts to appear. The interpretation of wave absorption and scattering done by Krautkrämer and Krautkrämer (1990) was expressed by Arroyo (2001) as follows: “...scattering of elastic waves, i.e. partial reflection and deviation of energy, is due to the granular nature of (any) material, and dependent on the relation between the wavelength of the impeding wave and the size of the obstacle
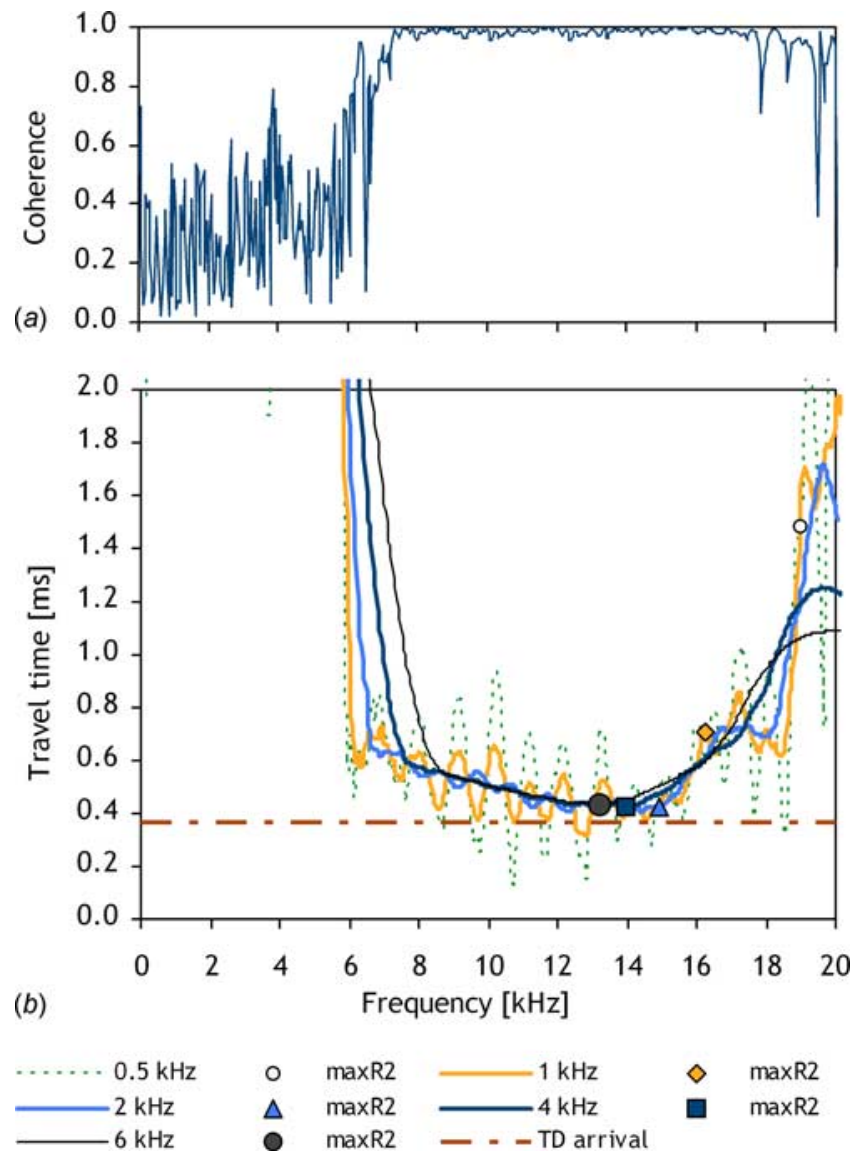

FIG. 17-FD analysis results for Toyoura sand $\left(p^{\prime}=400 \mathrm{kPa}\right)$ : (a) coherence; (b) travel-time spectra.

(grain) or inhomogeneity. This introduces a frequency dependence on attenuation and imposes a practical higher limit to the movement frequency."

Using grain size and $V_{S}$ values, Arroyo (2001) presented a graph in which the frequency limit is inversely proportional to the grain size, showing clearly that for a granular material, independently of its water content (or degree of saturation), the operating frequency range is relatively low, and hence frequencies above the order of $10 \mathrm{kHz}$ would pose serious attenuation problems for sands.

Both studies corroborate the present results, and the greater complexity of interpreting BE results on the Toyoura sand specimen seems to be explained by the dispersion due to the use of inappropriately high frequencies, at which the response of the sand is strongly attenuated.

\section{Conclusions}

This work has shown that the results presented from the frequencydomain method vary significantly for slight changes in the frequency window used in the analysis. The use of an automated tool enables to unbiased information regarding such variations to be obtained to assist the decision, as has been demonstrated with the two case studies.

The two soils used had different grain-size distributions, with one being tested completely saturated and the other in dry conditions. Both of these factors seem to have had an influence on the results. In particular, the occurrence of side reflections, which af- 
fect the quality of the received signals, is likely to be more pronounced in the dry sand than in the saturated Porto residual soil, which may explain the relatively greater difficulty in interpretation of the results from the Toyoura sand. The grain-size uniformity of the sand is also likely to attenuate at much lower frequencies than the residual soil, adding further complexity to BE testing results.

A framework is proposed for combining simultaneous and automated analysis of the coherence between the input and output signals in the time domain against input frequency and a graph of time versus frequency deduced from the sweep data (frequency domain). This procedure enables the variability, even at high coherence values, of the results from the sweep method to be dealt with and the travel time to be deduced from the highest correlation coefficient obtained from different moving windows. The most important conclusion from the work is that the combined use of timedomain and frequency-domain methods can aid effectively in the analysis and interpretation of BE tests in the triaxial apparatus.

\section{Acknowledgments}

This work was developed under the research activities of CEC from FEUP (Project POCTI/ECM/55589/2004), supported by FCT (Portuguese Science and Technology Foundation). The authors are grateful to Doctor Jorge Carvalho for his help in signal analysis. Cristiana Ferreira acknowledges the support of FCT (PhD Scholarship SFRH/BD/11363/2002).

\section{References}

Abbiss, C. P., 1981, "Shear Wave Measurements of the Elasticity of the Ground," Geotechnique, Vol. 31, No. 1, pp. 721-726.

Airey, D., Mohsin, A. K. M., and Donohue, S., 2003, "Obtaining Reliable $\mathrm{G}_{\max }$ Measurements," Proceedings of the Workshop on Current Practices of the Use of Bender Element Technique, Lyon, France.

Alvarado, G., and Coop, M. R., 2004, "Experience of Bender Element Measurements on a Variety of Materials," Workshop on Bender Element Testing of Soils, University College, London.

Anderson, D. G., and Woods, R. D., 1975, "Comparison of Field and Laboratory Shear Moduli," Proceedings of the Conference on In Situ Measurement of Soil Properties, Specialty Conference of the Geotechnical Engineering Division, ASCE, North Carolina, Vol. 1, pp. 69-92.

Arroyo, M., 2001, "Pulse Tests in Soil Samples," PhD Thesis, University of Bristol, UK.

Arroyo, M., Medina, L., and Muir, Wood D., 2002, "Numerical Modelling of Scale Effects in Bender-Based Pulse Tests," NUMOG VIII, G. N. Pande and S. Pietruszczak, Eds., pp. 589-594.

Arroyo, M., Muir, Wood D., and Greening, P. D., 2003, "Source Near-Field Effects and Pulse Tests in Soil Samples," Geotechnique, Vol. 53, No. 3, pp. 337-345.

Arroyo, M., Muir, Wood D., Greening, P. D., Medina, L., and Rio, J., 2006, "Effects of Sample Size on Bender-Based Axial $\mathrm{G}_{\mathrm{o}}$ Measurements," Geotechnique Vol. 56, No. 1, pp. 39-52.

Arulnathan, R., Boulanger, R. W., and Riemer, M. F., 1998, "Analysis of Bender Element Tests," Geotech. Test. J., Vol. 21, No. 2, pp. 120-131.

Biot, M. A., 1956, “The Theory of Propagation of Elastic Waves in a Fluid-Saturated Porous Solid, I. Low-Frequency Range, II. Higher Frequency Range," J. Acoust. Soc. Am., Vol. 28, pp. 168-191.

Blewett, J., Blewett, I. J., and Woodward, P. K., 1999, "Measurement of Shear Wave Velocity Using Phase Sensitive Detection techniques," Can. Geotech. J., Vol. 36, pp. 934-939.

Blewett, J., Blewett, I. J., and Woodward, P. K., 2000, "Phase and Amplitude Responses Associated with the Measurement of Shear-Wave Velocity in Sand by Bender Elements," Can. Geotech. J., Vol. 37, pp. 1348-1357.

Brignoli, E. G. M., Gotti, M., and Stokoe, K. H., II, 1996, "Measurement of Shear Waves in Laboratory Specimens by Means of Piezoelectric Transducers," Geotech. Test. J., Vol. 19, No. 4, pp. 384-397.

Brocanelli, D., and Rinaldi, V., 1998, "Measurement of Low Strain Material Damping and Wave Velocity with Bender Elements in the Frequency Domain," Can. Geotech. J., Vol. 35, pp. 10321040.

Burland, J. B., 1989, "Small is Beautiful-the Stiffness of Soils at Small Strains" Can. Geotech. J., Vol. 26, pp. 499-516.

Cooley, J. W., and Tukey, J. W., 1965, “An Algorithm for the Machine Calculation of Complex Fourier Series," Math. Comput., Vol. 19, No. 90, pp. 297-301.

Di, H. Benedetto, Geoffroy, H., and Sauzéat, C., 1999, "Sand Behaviour in Very Small to Medium Strain Domain," Proceedings of the 2nd Int. Conference on Pre-failure Deformation Characteristics of Geomaterials, Jamiolkowski, Lancellotta, and Lo Presti, Eds., Balkema, Rotterdam, pp. 89-96.

Dyvik, R., and Madshus, C., 1985, "Lab Measurements of $\mathrm{G}_{\max }$ Using Bender Elements," Proceedings ASCE Annual Convention: Advances in the Art of Testing Soils Under Cyclic Conditions, Detroit, Michigan, pp. 186-197.

Dyvik, R., and Olsen, T. S., 1989, " $\mathrm{G}_{\max }$ Measured in Oedometer and DSS Tests Using Bender Elements," Proceedings of the 12th International Conference on Soil Mechanics and Foundation Engineering, Rio de Janeiro, Vol. 1, pp. 39-42.

Fam, M. A., Cascante, G., and Dusseault, M. B., 2002, "Large and Small Strain Properties of Sands Subjected to Local Void Increase," J. Geotech. Geoenviron. Eng., Vol. 128, No. 12, pp. 1018-1025.

Fam, M., and Santamarina, C., 1995, "Study of Geoprocesses with Complementary Mechanical and Electromagnetic Wave Measurements in an Oedometer," Geotech. Test. J., Vol. 18, No. 3, pp. 307-314.

Ferreira, C., 2003, "Implementation and Application of Piezoelectric Transducers for the Determination of Seismic Wave Velocities in Soil Specimens. Assessment of Sampling Quality in Residual Soils," MSc Thesis, Faculty of Engineering, University of Porto (In Portuguese).

Ferreira, C., 2004, "Analysis of the Application of Different Interpretation Techniques on Bender Element Measurements on Toyoura Sand," Workshop on Bender Element Testing of Soils, University College London, (http://www.civeng.ucl.ac.uk/staff/ pdg/benders/UCL-cristiana. ppt, last accessed at 5 December 2007).

Ferreira, C., and Viana da Fonseca, A., 2005, "Report on International Parallel Tests on Bender Elements at the University of Porto,” Portugal, FEUP (http://www.civeng.ucl.ac.uk/staff/pdg/ benders/UCL-cristiana.ppt, last accessed at 5 December 2007).

Ferreira, C., Viana da Fonseca, A., and Santos, J. A., 2007, “Comparison of Simultaneous Bender Elements and Resonant 
Column Tests on Porto Residual Soil," Soil Stress-Strain Behavior: Measurement, Modeling and Analysis. A Collection of Papers of the Geotechnical Symposium in Rome, 2006, Ling, Callisto, Leshchinsky, and Koseki, Eds., Springer, Berlin, pp. 523535.

Foti, S., Lai, C. G., and Lancellota, R., 2002, "Porosity of FluidSaturated Porous Media from Measured Seismic Wave Velocities," Geotechnique, Vol. 52, No. 5, pp. 359-373.

Geoffroy, H., Di Benedetto, H., Duttine, A., and Sauzéat, C., 2003, "Dynamic and Cyclic Loadings on Sands: Results and Modelling for General Stress-Strain Conditions," Proceedings of Deformation Characteristics of Geomaterials, Lyon, France, 22-24 September, Balkema, Rotterdam, pp. 353-363.

Greening, P. D., and Nash, D. F. T., 2004, "Frequency Domain Determination of $\mathrm{G}_{0}$ Using Bender Elements," Geotech. Test. J., Vol. 27, No. 3, pp. 288-294.

Greening, P. D., Nash, D. F. T., Benahmed, N., Viana da, Fonseca A., and Ferreira, C., 2003, "Comparison of Shear Wave Velocity Measurements in Different Materials Using Time and Frequency Domain Techniques," Proceedings of Deformation Characteristics of Geomaterials, Lyon, France, 22-24 September, Balkema, Rotterdam, pp. 381-386.

Hardy, S., Zdravkovic, L., and Potts, D. M., 2002, "Numerical Interpretation of Continuously Cycled Bender Element Tests," Numerical Models in Geomechanics, NUMOG VII, Pande and Pietruszczak, Eds., Swets and Zeitlinger, Lisse, pp. 595-600.

Hight, D. W., Bennell, J. D., Chana, B., Davis, P. D., Jardine, R. J., and Porovic, E., 1997, "Wave velocity and stiffness measurements of the Crag and Lower London Tertiaries at Sizewell," Geotechnique, Vol. 47, No. 3, pp. 451-474.

Hoffman, K. Varuso, and Fratta, D., 2006, "The Use of Low-Cost MEMS Accelerometers in Near-Surface Travel-Time Tomography," GeoCongress 2006 Conference, Atlanta, GA, pp. 1-6.

Ismail, M. A., and Hourani, Y., 2003, "An Innovative Facility to Measure Shear-Wave Velocity in Centrifuge and 1-g Models," Proceedings of Deformation Characteristics of Geomaterials, Lyon, France, 22-24 September, Balkema, Rotterdom, pp. 2129.

Ismail, M., Sharma, S. S., and Fahey, M., 2005, “A Small True Triaxial Apparatus with Wave Velocity Measurement," Geotech. Test. J., Vol. 28, No. 2, pp. 1-10.

Iwasaki, T., and Tatsuoka, F., 1977, "Effects of Grain Size and Grading on Dynamic Shear Moduli of Sands," Soils Found., Vol. 17, No. 3, pp. 19-35.

Jamiolkowski, M., Lancellotta, R., and Lo Presti, D. C. F., 1995, "Remarks on the Stiffness at Small Strains of Six Italian Clays," Pre-failure Deformation of Geomaterials, Shibuya, Mitachi, and Miura, Eds., Balkema, Rotterdam, pp. 817-836.

Jardine, R. J., and Shibuya, S., 2005, "TC29 workshop: Laboratory tests. Report," Proceedings of the 16th International Conference on Soil Mechanics and Geotechnical Engineering, Osaka, Vol. 5, pp. 3275-3276.

Jovičić, V., 2004, "Rigorous Bender Element Testing," Workshop on Bender Element Testing of Soils, University College, London.

Jovičić, V., Coop, M. R., and Simic, M., 1996, “Objective Criteria for Determining $\mathrm{G}_{\max }$ from Bender Element Tests," Geotechnique, Vol. 46, No. 2, pp. 357-362.

Kaarsberg, E. A., 1975, "Elastic Wave Velocity Measurements in Rocks and Other Materials by Phase-Delay Methods," Geophysics, Vol. 40, pp. 855-901.
Krautkrämer, J., and Krautkrämer, H., 1990, “Ultrasonic Testing of Materials," 4th Ed., Springer-Verlag, Berlin.

Lee, J. S., and Santamarina, C., 2005, "Bender Elements: Performance and Signal Interpretation," J. Geotech. Geoenviron. Eng., Vol. 131, No. 9, pp. 1063-1070.

Leong, E. C., Yeo, S. H., and Rahardjo, H., 2005, "Measuring Shear Wave Velocity Using Bender Elements," Geotech. Test. J., Vol. 28, No. 5, pp. 488-498.

Mancuso, C., Simonelli, A. L., and Vinale, F., 1989, "Numerical analysis of in situ S-wave measurement," Proceedings 12th Int. Conf. on Soil Mechanics and Foundation Engineering, Rio de Janeiro, Brazil Vol. 1, pp. 277-280.

Mohsin, A. K. M., and Airey, D. W., 2003, “Automating $\mathrm{G}_{\max }$ Measurements in Triaxial Tests," Proceedings of the 3rd International Symposium on Deformation Characteristics of Geomaterials, IS-Lyon '03, 24 September, 2003, pp. 73-80.

Pennington, D. S., 1999, “The Anisotropic Small Strain Stiffness of Cambridge Gault Clay," PhD Thesis, University of Bristol, UK.

Pennington, D. S., Nash, D. F. T., and Lings, M. L., 2001, "Horizontally-Mounted Bender Elements for Measuring Anisotropic Shear Moduli in Triaxial Clay Specimens," Geotech. Test. J., Vol. 24, No. 2, pp. 133-144.

Rio, J., 2006, “Advances in Laboratory Geophysics Using Bender Elements," PhD Thesis, University College London, University of London.

Rio, J., Greening, P., and Medina, L., 2003, "Influence of Sample Geometry on Shear Wave Propagation Using Bender Elements," Proceedings of Deformation Characteristics of Geomaterials, Lyon, France, 22-24 September, Balkema, Rotterdom, pp. 963967.

Roesler, S. K., 1979, “Anisotropic Shear Modulus Due to Stress Anisotropy," J. Geotech. Engrg. Div., Vol. 105, No. GT7, pp. 871-880.

Sadek, T., 2006, “The Multiaxial Behaviour and Elastic Stiffness of Hostun Sand," PhD Thesis, University of Bristol, UK.

Sánchez-Salinero, I., Roesset, J. M., and Stokoe, K. H., II, 1986, "Analytical Studies of Body Wave Propagation and Attenuation," Geotechnical Report No. GR86-15, Civil Engineering Department, University of Texas at Austin.

Santamarina, J. C., Klein, K. A., and Fam, M. A., 2001, Soils and Waves-Particulate Materials Behavior, Characterization and Process Monitoring, John Wiley \& Sons, New York.

Santamarina, J. C., and Fam, M. A., 1997, "Discussion on 'Interpretation of Bender Element Tests"' (paper by Viggiani and Atkinson, 1995), Geotechnique, Vol. 47, No. 4, pp. 873-877.

Santos, J. A., 1999, "Soil Characterization by Means of Dynamic and Cyclic Torsional Tests. Application to the Study of the Behaviour of Piles Under Static and Dynamic Horizontal Loads," $\mathrm{PhD}$ Thesis, Technical University of Lisbon UNL-IST (in Portuguese).

Santos, J. A., Camacho-Tauta, J., Viana da Fonseca, A., and Ferreira, C., 2007, "Use of Random Vibrations to Measure Stiffness of Soils," EVACES'07 (submitted for publication).

Sasche, W. and Pao, Y-H, 1978, "On the Determination of Phase and Group Velocities of Dispersive Waves in Solids," J. Appl. Phys., Vol. 49, No. 8, pp. 4320-4237.

Schultheiss, P. J., 1983, "The Influence of Packing Structures on Seismic Wave Velocity in Sediments," Marine Geological Report No. 83/1, University College of North Wales.

Shirley, D. J., 1978, "An Improved Shear Wave Transducer," J. Acoust. Soc. Am. 63, No. 5, pp. 1643-1645.

Shirley, D. J., and Hampton, L. D., 1978, "Shear Wave Measure- 
ments in Laboratory Sediments," J. Acoust. Soc. Am., Vol. 63, No. 2, pp. 607-613.

Souto, A., Hartikainen, J., and Ozudogru, K., 1994, "Measurement of Dynamic Parameters of Road Pavement Materials by the Bender Element and Resonant Column Tests," Geotechnique, Vol. 44, No. 3, pp. 519-526.

Stokoe, K. H., and Woods, R. D., 1972, "In Situ Shear Wave Velocity by Cross-Hole Method," J. Soil Mech. and Found. Div., Vol. 98, No. SM5, pp. 443-460.

Stokoe, K. H. II, Joh, S.-H., and Woods, R. D., 2004, "Some Contributions of in situ Geophysical Measurements to Solving Geotechnical Engineering Problems," Proceedings of ISC-2: Geotechnical and Geophysical Site Characterization. Viana da Fonseca and Mayne, Eds., Porto, Portugal, 19-22 September, Millpress Science Publishers, Rotterdam, Netherlands. Vol. 1, pp. 97-132.

Sully, J. P., and Campanella, R. G., 1995, "Evaluation of in situ Anisotropy from Crosshole and Downhole Shear Wave Velocity Measurements," Geotechnique, Vol. 45, No. 2, pp. 267-282.

Viana da Fonseca, A., 2003, "Characterizing and Deriving Engineering Properties of a Saprolitic Soil from Granite, in Porto,"
Characterization and Engineering Properties of Natural Soils. Swets and Zeitlinger, Lisse, pp. 1341-1378.

Viana da Fonseca, A., Carvalho, J., Ferreira, C., Santos, J. A., Almeida, F., Pereira, E., Feliciano, J., Grade, J., and Oliveira, A., 2006, "Characterization of a Profile of Residual Soil from Granite Combining Geological, Geophysical and Mechanical Testing Techniques," Geotech. Geologic. Eng., Vol. 24, No. 5, pp. 1307-1348.

Viggiani, G., and Atkinson, J. H., 1995, "Interpretation of Bender Element Tests," Geotechnique, Vol. 45, No. 1, pp. 149-154.

Yamashita, S., Fujiwara, T., Kawaguchi, T., Mikami, T., Nakata, Y., and Shibuya, S., 2007, "International Parallel Test on the Measurement of $\mathrm{G}_{\max }$ Using Bender Elements," organized by Technical Committee 29 of the International Society for Soil Mechanics and Geotechnical Engineering (http://www.jiban.or.jp/ e/tc29/BE_Inter_PP_Test_en.pdf, last accessed at 5 December 2007).

Zeng, X., and Grolewski, B., 2005, "Measurement of Gmax and Estimation of $\mathrm{K}_{0}$ of Saturated Clay Using Bender Elements in an Oedometer," Geotech. Test. J., Vol. 28, No. 3, pp. 264-274. 